\title{
Prevalence and Factors Associated with Musculoskeletal Pain among Secondary School Students
}

\author{
Salim Nauzeer ${ }^{1 *}$, Vishal Chandr Jaunky ${ }^{2}$
}

\author{
${ }^{1}$ Open University of Mauritius, MAURITIUS \\ ${ }^{2}$ Lulea University of Technology, SWEDEN \\ *Corresponding Author: snauzeer@yahoo.com
}

Citation: Nauzeer, S., \& Jaunky, V. C. (2021). Prevalence and Factors Associated with Musculoskeletal Pain among Secondary School Students. Aquademia, 5(2), ep21008. https://doi.org/10.21601/aquademia/10964

ARTICLE INFO

Received: 8 Jan. 2021

Accepted: 17 Mar. 2021

\begin{abstract}
The purpose of this paper is to examine the factors associated with the occurrence of shoulder pain, neck pain, upper back pain and lower back pain with particular focus on carrying schoolbags. A questionnaire containing a range of musculoskeletal pain related information was designed specifically for a group of schoolchildren aged 11 to 20 years and distributed to Grade 7 to Grade 13 students attending three main secondary education schools in Mauritius over the period July 2017 to February 2018. A total of 1048 questionnaires were circulated out of which 849 were useable. The study analyzed the impact of socio-economic characteristics, student perception of use of tablets, type of schoolbag, private tuition, performance, duration of bag carriage and anthropometric characteristics. Logistic regressions models were applied to inspect how those recorded factors contribute to the occurrence of musculoskeletal pain. The main findings in this paper indicate that students from single-sexed girl and mixed schools relative to boys' schools, student perception of tablet use, backpack schoolbag relative to handbag and shoulder-bag, performance, total weight and excess weight of schoolbags have significant positive impact on musculoskeletal pain. The results point towards the importance of raising awareness among students to achieve a positive musculoskeletal health. Information obtained is deemed to affect schoolbook and equipment-carrying behaviour and future choice of schoolbag type.
\end{abstract}

Keywords: students, musculoskeletal pain, BMI, gender, weight of bags

\section{INTRODUCTION}

Mauritius has embarked into a new education system since 2017 to remedy the inconveniences caused by past three education systems ranging from 'rat race' and enormous pressure on students to get best grades and A+ to secure seats in star schools. This new system is intended to shape our students in the best possible ways so that they become future assets as human capitals in the competitive technological labour market. The government has set several objectives in the new education system ranging from holistic development and the completion of secondary education up to grade 13 with a new primary school curriculum offering technological use, physical health and education as shown in Table 1 and Table 2 , respectively.

The key terms emerging from the six objectives of the NYCBE (Table 1) are 'knowledge, foundational skills, attitudes, moral responsibility, values, strong identity, development, equitable learning, achievement, recognition, schooling, human capital and sustainable development.' When examined from an education researcher's point of view, these objectives correlate two branches of psychology and the human capital (HC) theories. This affirms the government's awareness of the existing psychological and health plight and accordingly the proposed objectives are expected to reside in the applications of these theories. It is implicit to determine the involvement of psychology theories in education psychology and personality psychology. In the human capital theories, health occupies a major value.

The first three objectives are embedded in educational psychology and personality psychology. Educational psychology is the scientific field which draws on and combines numerous psychological and behavioural theories to improve the understanding of teaching as well as learning strategies. It is griped with the concepts of motivation, intelligence, memory, cognition, intellectual development, evaluation and assessment (Larson, 2009). Personality psychology is the branch of psychology that described by a set of traits or fixed set of patterns of the thought patterns, feelings, and behaviours that make each unique (Feldt et al., 2010). Skills and knowledge represent a sort of capital, and there is a purposeful funding so that its development may bring the most unique features to the economic system (Schultz, 1961). 
Table 1. Nine Year Continuous Basic Education (NYCBE) Objectives

1 Equip all students with knowledge, foundational skills and attitudes leading to an empowered 2030 citizenry.

2 Inculcate in all students a sense of moral responsibility, a set of values and a strong identity for the country.

3 Promote the holistic development of all students.

4 Provide equitable Learning for All opportunities to attain high levels of achievement.

5 Achieve a smooth transition to and completion of secondary education.

6 Give greater recognition to the value of Technical and Vocational Education and Training (TVET) in building human capital and for

sustainable development.

(Source: Author's own)

Table 2. The Primary School Curriculum in Nine-Year Continuous Basic Education

\begin{tabular}{lll}
\hline Core Subjects & Option Core Language Subjects & Non-core Subjects \\
\hline English & Arabic, Hindi & Oral expression \\
\hline French & Mauritian kreol & Information and communication technology \\
\hline Mathematics & Marathi, Modern Chinese & Physical education and health \\
\hline History and Geography & Ourdou, Tamil & Arts: Dance, theatre, music and painting \\
\hline Sciences & Telegu & Road security education \\
\hline
\end{tabular}

(Source: Author's own)

The objectives four, five and six are anchored on education and health issues in the human capital theory. The HC theory acknowledges early youth investments as influential in shaping future outcomes including high school graduation, post-secondary enrolment, employment, health, income and wealth. It gives importance to skills or abilities to lifetime success, health outcomes (Goldin \& Katz, 1999), marriage, fertility, social cohesion, immigrant assimilation, entrepreneurship and criminal behaviour (Quiggin, 1999). In brief, HC encourages the studying of these issues within a comprehensive framework for the whole life course (Robinson, 2014). Investment in education, training and health are supposed to increase productivity under HC, and more health human capital permits people to be more fruitful in work and labour more intensively in the lifetime (Goldin \& Katz., 1999).

This study probes deeper in the HC theory and investigates on the determinants of musculoskeletal pains. A survey is performed and the quantitative ordered logistic regression models are used to expose the results. The findings may help to identify risk factors and isolate students prone to MSP and recommendations may help towards achieving a healthier and more productive future. The research question in this investigation is:

“What are the factors causing MSP among students?”

\section{DETERMINANTS OF MUSCULOSKELETAL PAINS}

\section{Theories on Health Education}

Education and health have common interests. Merging these interests permits schools to turn out to be better placed to appreciate learning, teaching and working. According to a recent report on health, the emphasis is being laid on critical policies, approaches and gaps to promote healthy schools. Many recent European conferences messages are pinpointing on health promoting schools including the proposal of steps to take to strengthen school health promotion. Education is remarkably vital for many of the policy outcomes that the general public and politicians take into account. At an individual level, education offers opportunities for a successful life and at a national level, a reserve of skills matters massively for prosperity and growth rate (Burgess, 2016). Among the objectives of the NYCBS (Table 1) towards equipping all students towards future citizenry, provide equitable learning and to attain high levels of achievement, there lies the theory of HC which can be represented as follows:

\section{HC = Education, health and other human skills that can raise productivity}

Health is an important pillar in the HC theory and education is supposed to contribute towards improving the health and productivity of students and the public in general. Many students are debarred from these benefits and are vulnerable to lurking vices like smoking, alcoholism and drugs. According to world drug report (2018), cannabis is the most widely used drug, both among the general population and among students in most countries.

The education system normally offers a preventive mechanism against these evils, but still, many students become preys. Non-communicable diseases like obesity, hypertension, and MSD are also gaining popularity in disturbing the normal educational trend (Arghavani et al., 2016; Malhotra \& Nistane, 2016). Weakened musculoskeletal health is accountable for the utmost loss of productive life years in the labour force compared with other noncommunicable diseases (Schofield et al., 2015). BP in children was rare before the late 1980s, but now it is becoming a serious problem (Balague et al., 1998; Shahid et al., 2018; Springett \& Wise, 2007).

MSD has a financial impact in billions due to associated medical costs due short and long-term work absenteeism (Deeney \& O’Sullivan 2009; Hogg-Johnson et al., 2009). Thus, it is also a socioeconomic problem (Hoy et al., 2014; Kędra \& Czaprowski, 2013). For instance, students that experience LBP in childhood have a higher risk of suffering from this ailment in later life (Watson et al., 2002). Musculoskeletal health is essential for maintaining economic, social and functional independence, as well as human capital across the life course (Briggs et al., 2018). Research studies and preventive measures participating in the soothing and alleviation of MSP are strongly recommended as it indirectly helps the education and 
human capital. MSP are serious issues. Therefore, this study examines the prevalence and factors associated with MSP among secondary school students. It will help to make proposals in the NYCBE so that MSP does not become a handicap to the learning and development of our future HC.

According to Syazwan et al. (2011), some causes of MSP in students comprises; gender-female is more common, agechildren at 10-13 years, heavy school bags particularly carried on one shoulder, incorrectly packed backpacks, inactive lifestyle, soft tissue injuries. Some students usually forget the pain and seeking medical treatment is rare (Burton et al., 1996). MSP can even be chronic depending on specific factors, and while some students take less than a month to recover, for others it may be permanent (Salminen et al., 1992). Evidence also indicated that MSP is associated with some risk factors including age, body mass index (BMI), education attainment, income level, and race (Callahan et al., 1996; Yelin, 1997). Low socioeconomic status, family income and other factors are linked with experiencing chronic MSP in adolescence (McBeth \& Jones, 2007). Therefore, for the holistic development of all students and an empowered citizenry on 2030, the study of the factors which contribute to pain among children is important.

\section{Age and Musculoskeletal Pains}

Age is a possible demographic factor that can explain the occurrence of pain in general. Mikkelsson et al. (1997a) reveals that MSP is diagnosed even in childhood. Moreover, both the prevalence and incidence of BP increase with age (Salminen et al., 1992). Numerous studies bear testimony that the occurrence of neck or shoulder complaints (Hakala et al., 2002; Siivola et al., 2004) and BP amplifies with age (Sato et al., 2008; Watson et al., 2002). Panicker and Sandesh, (2014) show there is an increase in MSP with age. In contrast, Dianat et al. (2013) reveal no connection between neck, shoulder or low back complaints and age but a weaker relation between age and neck pain (NP) is observed (Malik et al., 2017).

\section{Gender and Musculoskeletal Pains}

MSP is generally more prevalent in females than males. This trend can be already present in childhood (Mikkelsson et al., 1997b) and persists up to adulthood (Linton, 1990). Both age and gender explain the presence of lower back pains (LBP) (Balague et al., 1998). For example, dorsal pain (DP) and LBP is more likely in girls of age 14 than boys of the same cohort (Korovessis, 2004). MSP prevalence varies among adolescents and many studies reports females as being more susceptible to such pains (Dianat, 2013; Hakala et al., 2012). Besides, Siivola, (2003) suggests that females diagnose and state their symptoms more sensitively than males. According to Yeun (2017), neck pain (NP) and shoulder pain (SP) is linked to gender, mainly in women. However, Malik et al. (2017) dismiss the association between gender and NP.

\section{Location and Musculoskeletal Pains}

Geographical location denotes to the place where a school is situated whereas location is a particular place about other areas (Jovinius, 2015). Therefore, the site of school is either urban or rural in our local context. The factor 'student location' may have an impact on pain intensity as it is related to walking and duration of bag carriage (Aundhakar et al.,
2015). Studies report conflicting statistics on whether urban or rural locations can enhance pain intensity (Darmawan et al., 1992; Haq et al., 2005; Mwaka et al., 2014)). Some studies indicate no significant relations between location and MSP (AL-Qato, 2012), location and spinal pain (Lewandowski \& Lukaszewska, 2014), location and back pains (BP) (El-Nagar \& Mady, 2017).

\section{Parental Education, Family Income and Musculoskeletal Pains}

Socio-economic deficiencies are related to poor health among students (Power, 1991). But its connection to MSP is debatable. Hestbaek et al. (2008) approves that low parental educational is an indicator of the socio-economic status of the family and is associated with lower back pain (LBP) in children and adolescents. Similarly, Kumar et al. (2017) show that parental education is an explanatory factor of MSP in school going children and it also impacts daily life. A modest negative association can exist between parental education and LBP in young students (Leboeuf-Yde et al., 2002). Silva et al. (2014) show that parental schooling is not associated with LBP. Mikkonen (2016) reveals that socio-economic status is not reliably linked to LBP, but clusters of problems may favour LBP. According to Issa et al. (2016) fresh survey, small family members and high family monthly income provide ingredients to inhibit LBP.

\section{Tablet (e-book) and Musculoskeletal Pains}

With the current technological developments, there is a change from old-style education to the tablet-assisted learning environment (Uyal et al., 2017). The e-book is defined as an electronic version of the printed book (Siegenthaler et al., 2010) or written work in a digital format which can be readable by using e-readers, personal computer or mobile phone or tablet (Annand, 2008; Kang et al., 2009). Some studies commend the importance of such a change while others are against it, bearing in mind the adverse effects. For instance, Hashemi et al. (2011) underlines the efficacy of mobile learning on education and supports the notion of using mobile devices such as tablets as an educational tool. Accordingly, a secondary school manages to replace heavy schoolbags full of textbooks with Apple's lightweight tablet device, the iPad with the help of parents and teachers. Also, ebooks relief students from holding the heavy bags that may cause BP or spine bend (Embong et al., 2012). Other studies indicate many physical discomforts associated with tablet use including MSP in many regions of the body (Calisir \& Akdag, 2017; Lee et al., 2018; Uyal et al., 2017).

\section{Type of Backpack and Musculoskeletal Pains}

The type of school bags including backpacks, shoulder bags or handbags can boost discomfort in students in their sensitive growth and development period (Rontogiannis et al., 2017). Both the type of bag pack and style of bag carriage are associated with postural changes causing injuries in the shoulder, arms, hands and back. It is due to asymmetric load distribution (Yoon, 2014). According to some studies, the way in which the backpack is carried and its model correlate postural risks and BP in adolescents (Candotti et al., 2012; Fernandes et al., 2008; Melo-Marins, 2015). 
Carrying a bag over one shoulder brings postural changes which are in turn link to spinal pain. Other studies too suggest that one shoulder bag contributes to BP and NP (Siambanes et al., 2004). Research shows that at least $90 \%$ of students use backpacks in developed countries (Goodgold et al., 2002). There is an indication that a backpack is a healthier technique of carrying weight than a shoulder bag. One study indicates no association between the use of pack and the occurrence of LBP (Natasha et al., 2018).

\section{Tuition and Musculoskeletal Pains}

In today's competitive world, tuition brings additional weight to backpacks with additional items like books (Muppidi et al., 2019) and hence such students are more prone to MSP (George et al., 2015). A fresh study shows that children are expected to experience neck and SP, as well as the commonlyreported BP. Tuition can also have an indirect impact on a student's health as it requires extra fees and some students are compelled to work part-time jobs to fit the budget. McGrady and Moss (2018) illustrate this outlier case whereby the respective student suffers from chronic illness due to a parttime job to pay the tuition fee even after graduation.

\section{Performance and Musculoskeletal Pains}

The performance of students and the occurrence of MSP depend on the subject being examined. Subjects like sports and physical education involve effort, spinal mobility and flexibility of muscles and joints and they are associated with LBP (Fairbank et al., 1984; Triki et al., 2015). Vijay and Ide, (2016) indicate an association between procedure performance and musculoskeletal NP and BP in dental students. According to Sampaio et al. (2016), in all the grades, more than half of the students present postural changes or pain in the academic performance of their school functions. Shan et al. (2013) indicates that high performance of students is linked with lower BP, NP and SP as the students are less stressed.

\section{BMI and Musculoskeletal Pains}

Body mass index (BMI), which is a measure of body adiposity and is described as the weight (in kilograms) divided by height (in square meters), is also known to be related to the development of MSDs (Yang et al., 2014). BMI, stress and MSP'S are interrelated (Harding et al., 2014; Viester et al., 2013). Anthropometric measurements, weight and height, are carried out to as assess BMI study (Spiteri et al., 2017). One study measures BMI based on US references and groups BMI as underweight $(<5 \%)$, normal weight $(5 \%-<85 \%)$, overweight $(85 \%-<95 \%)$, and obese $(\geqslant 95 \%)$ and finds that higher BMI is significantly associated with low BP in males and females' students (Hershkovich et al., 2013). Many other studies associate high BMI to MSP (Kristjansdottir \& Rhee, 2002). Spiteri et al. (2017) indicate BMI is an explanatory factor of BP in children between 8 and 13. There are also contrasting studies showing no such association with MSP (Kwon, 2006; Tantawy et al., 2017).

\section{Duration of Carriage}

Clinicians are frequently requested for instruction on school bag carriage and its contribution to back and NP (Wigram, 2002). The physical exposure of bag use is determined by its weight and also by the duration and method of carriage. Grimmer and Williams (2000) reveals that a longer duration of carrying a school bag increases the risk BP. Risk factors for musculoskeletal agony are connected with the duration of schoolbag carriage combined with effects of hefty loads, load shape and size and location of the load on the body (Chansirinukor et al., 2001).The presence of extensive weight burden on the back and its long duration of carriage result in first signs of the lower BP syndrome (Haselgrove et al., 2008; Paušić et al., 2013). Students carrying heavy backpacks from home to school on walking increase their relative risk of BP.

\section{Length of Straps}

Walking with a bag makes use of muscle activities including right upper trapezius, left upper trapezius, right erector spinae and left erector spinae. The length of straps may impact these muscle activities. The difference of straps length is seen to have significant influence on body posture (Brzek et al., 2017). Yoon (2014) finds no significant correlation between these activities and the length of straps of bags. Still, some studies are in favour of two straps bags relative to one strap as it is believed to be ergonomic (Grimmer et al., 1999; Springett, 2007).

\section{Weight and Excess Weight}

Schooling coincides with the sensitive growth periods of students and musculoskeletal changes (Milbradt et al., 2011; Rodrigues et al., 2008). Children at this age are vulnerable to a number of factors that predispose them to the occurrence of bad posture and postural changes due to excessive loads on these structures are very likely to occur (Brackley \& Stevenson, 2004; Hong \& Cheung, 2003; Pascoe et al., 1997). The amount of schooling materials that students carry is almost the same per grade but differs across grades. The weight of students varies greatly due to many reasons including age and genetics. Each student is differently affected by the weight of their bags. This exposes students to many health issues, mainly MSP (George et al., 2015). The recommended bag pack weight by health organizations diverges ranging from not exceeding $5 \%$ to $20 \%$ of the student's body weight (Rai \& Agarawal, 2013) but the most convincing figures is not to exceed $10 \%$ of their body weight (Drzał-Grabiec, 2013; Goodgold et al., 2002; Moore et al., 2007). Many studies indicate that students carry bag packs greater than $10 \%$ of their body weight (Al Hazzaa, 2006; Limon et al., 2004). Heavy bag packs are in turn associated with MSP (Papadopoulou et al., 2014; Paušić \& Rausavljević, 2009; Paušić et al., 2013; Walicka-Cupry et al., 2015).

\section{OLS Technique and Musculoskeletal Pains}

There are various examples of studies using OLS techniques in the study of MSP in student (Alshagga et al., 2013; Dianat et al., 2014; Papadopoulou et al., 2014; Tantawy et al., 2017). It is always wise to have a notion of the statistical technique being utilised for practical usage and reliable results. Ragnar Frisch (1970) is usually credited for being the founder of the term 'econometrics. Econometrics seeks at giving empirical content to economic relationships by connecting economic theory, economic data, and statistical methods.

A 'theory without measurement' and a 'measurement without theory’ cannot fully explain an economic event. 
Economic data are entirely from non-experimental sources, and the researchers can just examine the expected experiments that occur making it more likely an observational science. In economics, it is difficult to exactly replicate past events with attempts to solve problems by isolating effects because the social, economic, and political orders are everchanging. Thus, researchers have to consider many options and account for comparison between the past, present, and future. Such a study will require learning about finite sample properties and estimation procedure in econometrics which is commonly referred to as ordinary least squares (OLS) (Fomby et al., 1984).

The general framework for regression analysis, deriving the OLS estimator and discussions about its properties then come into interplay. The method of OLS is a process to determine the best fit line to data using simple calculus and linear algebra as proof (Miller, 2006). The attempt is to find a direct relationship between the dependent variable and the independent variables based on certain hypotheses. Experimental error and the probability that the fundamental relationship may not be precisely linear render the link between the two variables approximately linear. So, it is somewhat impossible to expect perfect linear relationships between variables, but a careful analysis of the evidence will confirm that the method is computationally feasible and it is capable of huge generalisations.

OLS method is based on certain assumptions, and it is crucial to learn about them to avoid misuse and give incorrect results for the econometrics tests performed. The key assumptions used to derive the OLS estimators in linear regression models are: linear regression model with linear parameters, random sampling, the conditional mean $=0$, no multicollinearity, no autocorrelation, the number of observations should be higher than the number of parameters, random error terms, the error terms should be normally distributed etc. (Wooldridge, 2015). Satisfying all the assumptions is best but the violation of assumptions should not lead to abandoning econometric test. Applying the correct fixes and rerunning the model is a possible solution for are the liable econometric test.

\section{METHODOLOGY FOR MUSCOSKELETAL PAINS}

Productivity closely associates with health status, and MSP is one of the leading causes of deficiency in the labour force. MSP usually starts at a young age at school and deepens its roots with time, and if it is not identified and given due attention, serious MSD may occur. The policymakers are well aware of the adverse impacts of poor health in the labour market, and the government is right in providing a series of non-core subjects like the oral expression, ICT, art forms like dance and road safety education as indicated in Table 2 . The provision of tablets and reduced weight of bags by using termwise books are all measures and signs that the health of student's counts and it is treated as a serious issue.

MSD is first in the list of non-communicable diseases, and these health observations are based on international recommendations. For example, the recommended bag pack weight by health organizations diverges ranging from not exceeding $5 \%$ to $20 \%$ of the student's body weight (Rai \& Agarawal, 2013) but the most convincing figures is not to exceed $10 \%$ of their body weight (Drzał-Grabiec, 2013; Goodgold et al., 2002; Moore et al., 2007). Each student is differently affected by the weight of their bags, and this exposes students to many health issues, mainly MSP (George et al., 2015). National studies on MSP issues for students is scanty if not non-existing, and the situation demands an immediate national study so that the determinants of MSP are isolated and due recommendations are made.

\section{The Selection Criteria and Hierarchical Level}

The government manages public or state schools. A nongovernment association, such as a cathedral or any private institution can also control private schools. There are two types of private school namely government-dependent and government-independent. Government-dependent private schools are managed autonomously but collect more than $50 \%$ of their core funding from the government whereas independent ones get less. In Mauritius, all secondary schools are regularised by the government summing up to only two school categories, state and government-dependent private schools. Accordingly, these schools receive grants by the government meaning they are accountable for their academic and financial results.

The selection criteria included respondents who are students from secondary schools in Mauritius. Mauritius is a small island and any secondary school consists of students from both rural and urban locations. Besides, free bus transport to all students renders possible accessibility to any school across the island. Secondary schools are state school or private school and single sexed or mixed resulting into distinct categories of respondents. For the survey, two singled-sex schools (boys and girls) and two mixed schools were selected. On overall, the sample comprises of students from a state secondary school namely Forest side Boys SSS and three private aided secondary schools; Labourdonnais college (Mixed), MEDCO Cassis (Mixed) and Islamic College Girls (confessional secondary school). Two specific regions, the north (Port-Louis) and the central part (Curepipe) of Mauritius were chosen covering two of the four educational zones in Mauritius.It is worth noting that to conduct surveys at various schools is a sensitive issue and requires special permission from parents and rectors. Due to limited time factor like the availability of free periods to conduct surveys in each class and the approaching third term examinations, it was difficult to cover all the educational zones. Given that educational zones are assumed to be equitable as indicated in Figure 1, three schools from Zone 1 (Labourdonnais College (Mixed), MEDCO Cassis (Mixed) and Islamic College Girls (confessional secondary school) and one school from Zone 3 (Forest side Boys SSS) were selected. It is important to note that there is a fair division of location of secondary schools under the four education zones as indicated in Figure 1 and maintained by the NYCBE.

On overall, all possible types at student and school levels were included in the research survey. The rectors of state schools and managers of private schools occupy the highest 


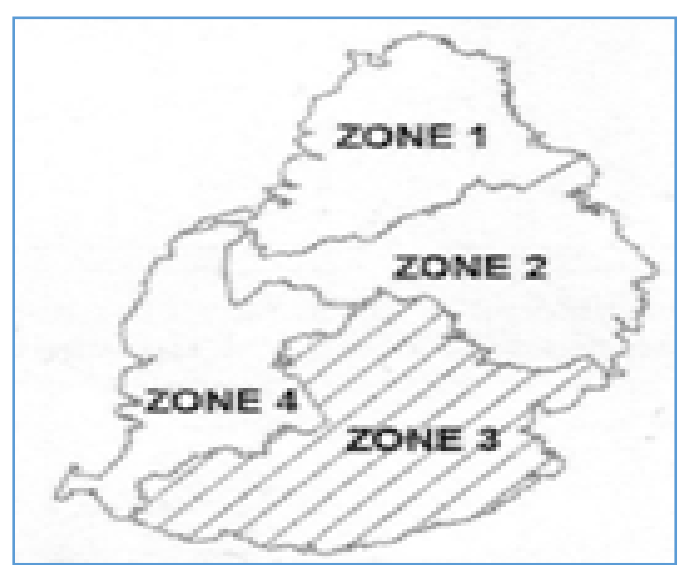

Figure 1. Education Zones in Mauritius

(Credit: Ministry of Education, Tertiary Education, Science and Technology, 2020)

position within the school. Permissions were granted from the respective school's rectors and managers as illustrated in Appendix B (B1 to B5) to conduct the surveys on students with age group varying from 11 to 18 years old. Each student was free to participate in the survey and they had the choice to answer or leave any question unanswered and even leave the survey at any moment.

\section{The Questionnaire and its Justification}

The analysis and detection of musculoskeletal symptoms of different persons in different parts of the globe using indirect methods (questionnaires) require the standardisation of the evaluation questions (López-Aragón et al., 2017). Such a questionnaire has been developed, and it is widely used under the name of the Nordic Musculoskeletal Questionnaire (NMQ) (Holman, 1966). Studies in MSP usually adapts from this standardised Nordic Questionnaire with modification to facilitate the comparison of results with other results in literature (Alshagga et al., 2013). This practice of adaptation is also observed in a study utilizing the Neurophysiology of Pain Questionnaire to assess understanding of pain neuroscience originally based on postgraduate pain medicine exam papers (Springer et al., 2018). The NMQ is designed to screen the existence of musculoskeletal pain (Alsalameh et al., 2019) and it is referred to as a reliable and valid screening tool in a recent research regarding the prevalence of MSP (Hendi et al., 2019).

Reliability tested by a test-retest method and it shows identical answers ranging from $78-100 \%$ while the validity tested in comparing to the clinical history of musculoskeletal pain of participants and it shows identical answers ranging from $80 \%$ to $100 \%$. NMQ provide useful and reliable data in relation to musculoskeletal pain. The actual study's questionnaire utilizes concepts from similar questionnaires and it adapts part of NMQ to capture MSP in its health section. The questionnaire consists of five sections in English language, but only three sections (A, B and D) are relevant to MSP.

Extracts of the questionnaire are shown in Figure 2(a)2(c). The first section includes questions regarding socioeconomic indicators (age, gender, grade, location, parental education, parental income level and family size). The second section deals with English performance and school facilities (student's perceptions of the use of a tablet to replace books and private tuition). Finally, Figure 2(d) in section D is on health status captures anthropometric measures (height and weight of students), weight of bags, type of bags, length of bag straps, symptoms of potential musculoskeletal injuries and duration of bag carriage.

A pilot testing of the questionnaire included 90 randomly chosen students, 30 educators and 5 rectors for corrections and proofreading and the required changes were made to enhance reliability. After the anthropometric measurements, the students completed questionnaires consisting of Likert scale, close-ended and branching questions.

Dear participant,

As part of our research project entitled: "Determinants of Academic Performance at Secondary School Level", we would be thankful if you could support us in the study by filling in the questionnaire. We assure you that all information provided will be used exclusively for the purpose of this study. Thanking you for your valuable time and collaboration.

Section A: Socio-Economic Indicators

1. Ageinu

2. Gender: $\square$ Male $\square$ Female

3. In which class are you?

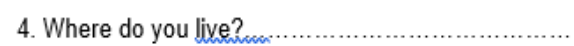

5. Level up to which your parents have studied:

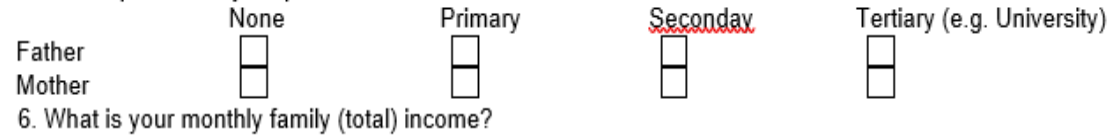

6. What is your monthly family (total) income?

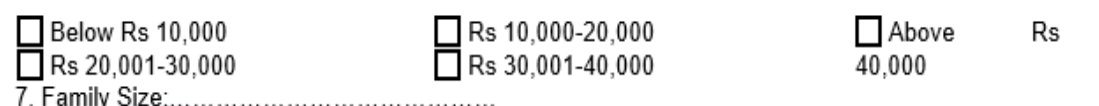

Figure 2. (a): Questionnaire Extract Showing Section A 
Section B: Performance and School Facilities

8. What is your last year's final exam grade/percentage?

Mathematicsinu

Overall Resultiwn .................................

Please show your approval with each of the statement below:

[Note: 1=Strongly Disagree, 2=Disagree, 3=Neither Agree nor Disagree, 4=Agree, 5=Strongly Agree]

9. Educators are good at explaining things

10. Educators have made the subject interesting.

11. Educators are role-models.

12. Educators' dress-code and appearance distract me.

13. The use of creole language by educators facilitates learning

14. I prefer CPE examinations compared to the Form III National Exam.

15. Some books should be replaced by tablets at school.

16. Specialists rooms (laboratories, workshops, art computer rooms, etc.) are of satisfactory quality

17. The sport facilities (gymnasium, football pitch, basket ball pitch, etc.) are of satifactory level.

18. The options offered (e.g. science, economics, etcul) are according to my aspirations.

19. I am often subject to bullying-attacks from students.

20. I take private tuitions.
If yes, answer the following or else skip this section:

No

If yes, answer the following or else skip this section:

21. I take tuitions because I do not learn well from educators at school.

22. My parents oblige me to take private tuitions.

23. My total monthly tuition fees
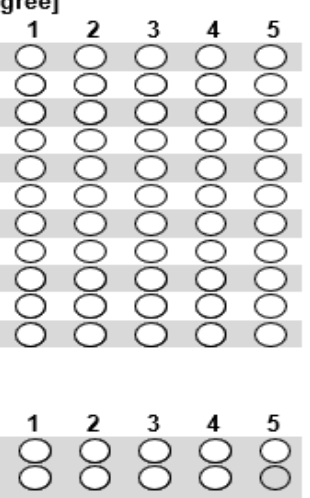

Page 1

(b)

\section{Section C: Motivations}

Please show your approval with each of the statement below:

[Note: 1=Strongly Disagree, 2=Disagree, 3=Neither Agree nor Disagree, 4=Agree, 5=Strongly Agree]

24. I feel completely absorbed by what I am learning in class.

25. I feel satisfied when I accomplish difficult academic activities (e.g. classwork, exams, etc.)

26. I am learning because I want to have "the good life" (e.g. good salary) later on.

27. I am learning to get personal recognition (e.g. certificate during prize-giving ceremony).

28. I really feel that I am wasting my time at school.

29. I once had good reasons for going to school, however, now I wonder whether I should continue.

30. Whether the subject content is difficult or easy, I am confident that I can understand it.

31. I am sure I can do well in any test.

32. I feel most satisfied when I am able to solve a difficult problem by myself.

33. When I make a mistake, I try to find out why.

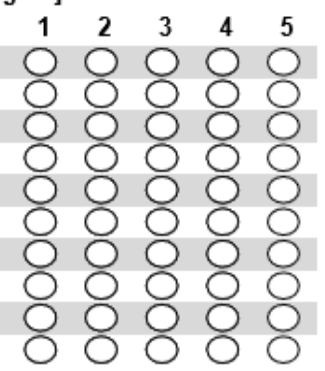

(c)

\section{Section D: Health Status}

34. Heightinn ….............................

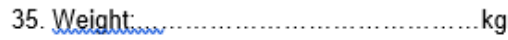

36. At school, I usually eat food from: $\square$ Home $\quad \square$ Canteen $\square$ Both

37. Type of bag: $\square$ Back pack $\square$ Shoulder bag $\square$ Hand bag

38. Weight of bags: ...

39. Length of straps of school bagim

$\mathrm{cm}$

40. Symptoms of injuries:

Sometimes

1 = Lower Back

Pain 2 = Upper Back

Pain

$3=$ Shoulder Pain

$4=$ Neck pain

41. Duration of daily carriage of bag while walking or standing

42. Price of bag: Rs musculoskeletal

Absent Always Present

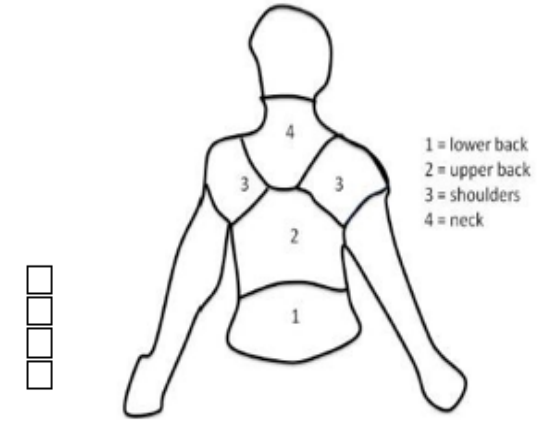




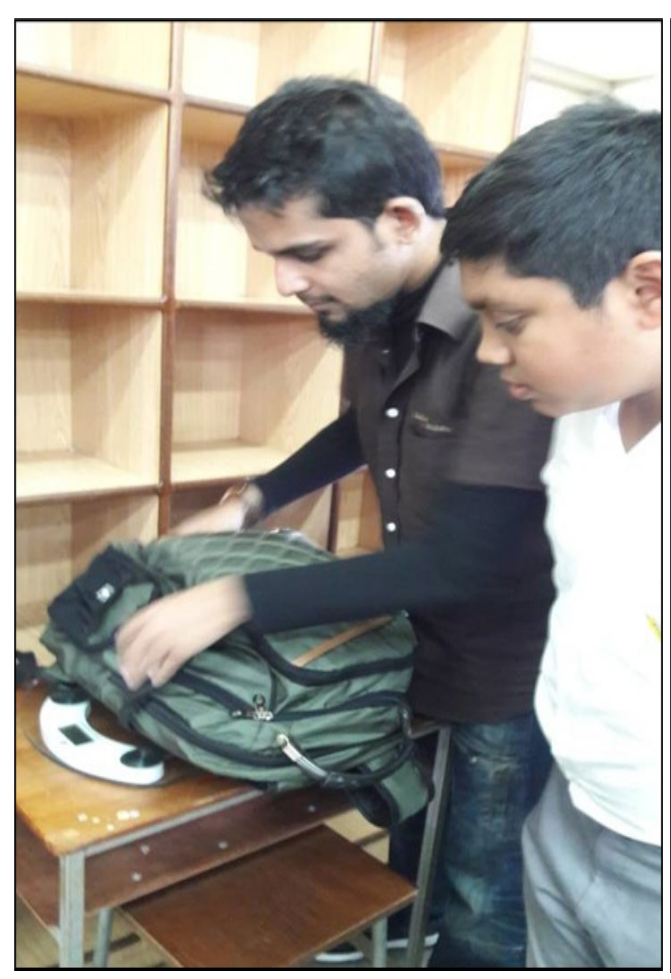

(a)

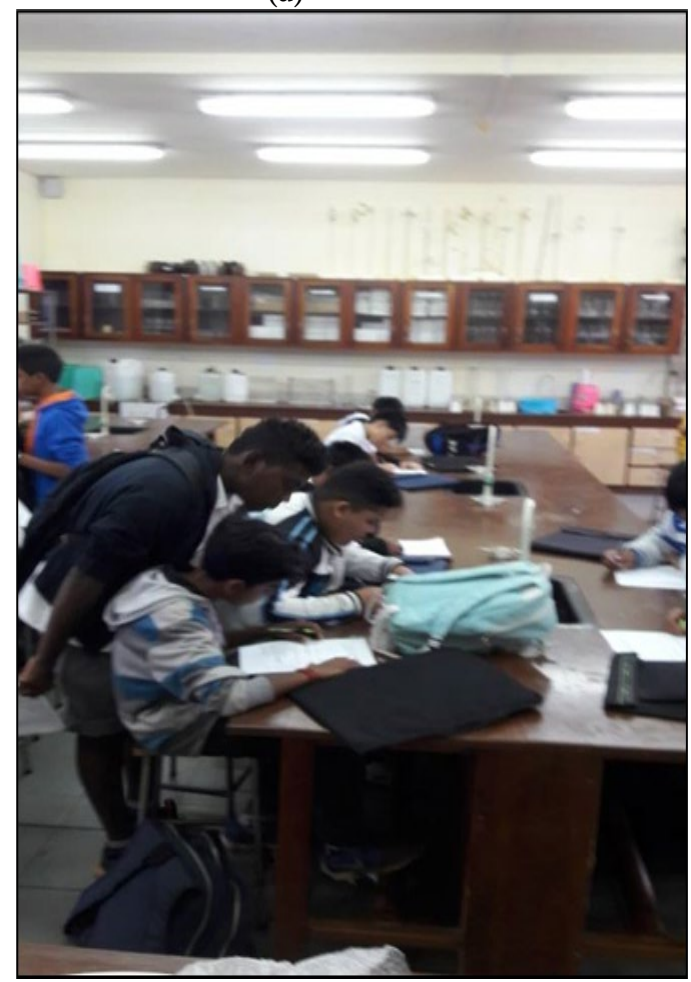

(c)

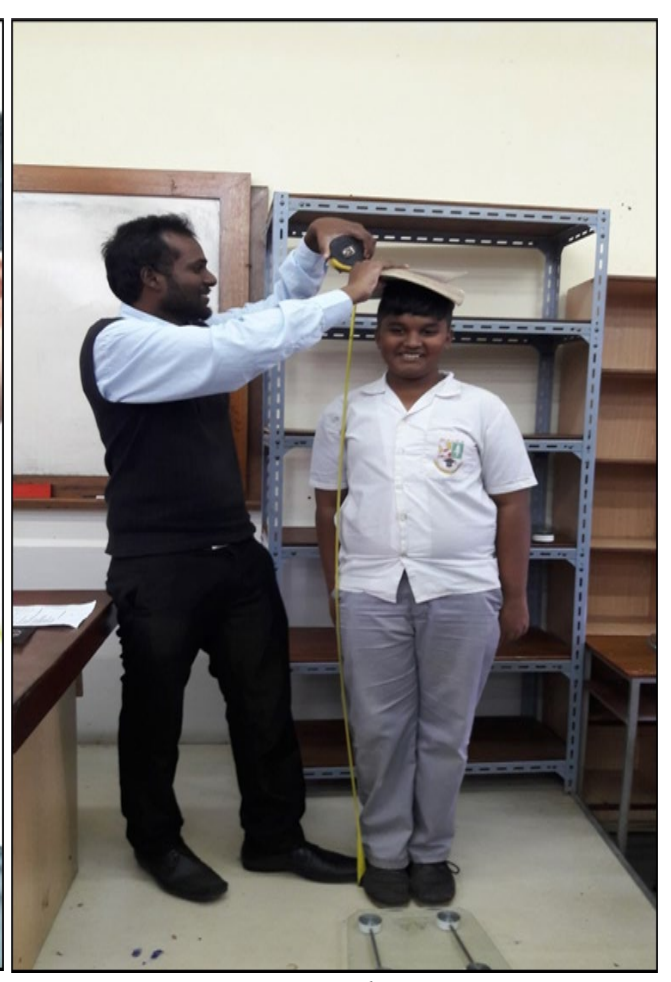

(b)

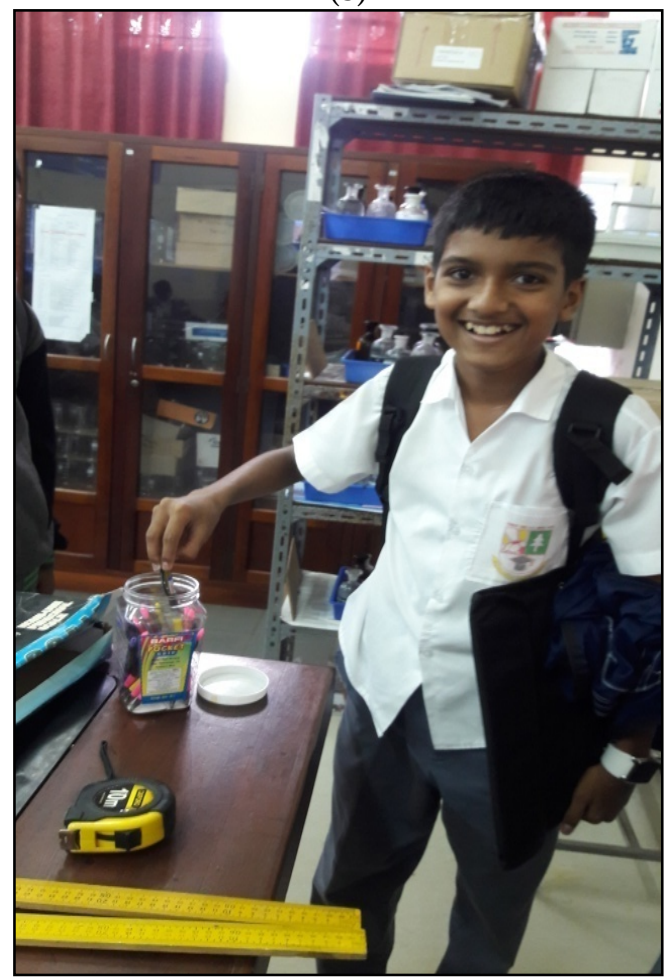

(d)

Figure 3. (a): Measuring student's bag weight; (b): Measuring Student's BMI; (c): Students Filling Questionnaire; (d): A Pen as Token

(Source: Author's own)

Figure 3(a), 3(b), 3(c), and 3(d) show the survey carried with grade 9 students whereby bag weights, BMI measurements, questionnaire fillings and a pen is given as a token to a student after completing the study. The mode of transportation was not included in the model because most students use free public bus transport compared to private, making further analysis unnecessary. The level of significance was set at $\mathrm{p}<0.1$ at most. The data are not normally distributed and are categories. Subsequently, logistic regressions are applied to examine the differences in age, gender, location, father education level, mother education level, total family income, perception about replacing some books with tablets, bag pack, tuition, performance, BMI, carriage, length of bag straps, weight and excess weight with pain and with regionspecific pain. 


\section{Regression Analysis and the Model}

A set of regression coefficients predicting the probability of MSP can be estimated by the use of logistic regressions. First, a binary logistic regression for overall MSP can be represented as:

$$
\ln \left(\frac{\operatorname{prob}(M S P)}{1-\operatorname{prob}(M S P)}\right)=\delta^{\prime} x_{i}+\mu_{i}
$$

where $\delta^{\prime} x_{i}$ is a vector of covariates and $\mu_{\mathrm{i}}$ is the error term for the ith individual. Ordinal logistic regression is used to predict an ordinal dependent variable given one or more independent variables.

Within the ordered logit framework, the categorical dependent variable which exhibits ordered multinomial outcomes for each respondent $i$, assuming $y_{i}=1,2, \ldots, m$. The categorical outcomes with regards to specific MSP are as "Absent", "Sometimes Present" and "Always Present" The model can be represented as:

$$
y_{i}=j \mu_{j-1}<y_{i}^{*}<\mu_{j}, j=1, \ldots, m
$$

where the latent variable $y^{*}$ is assumed to be a linear function of a vector of covariates $\chi^{\prime}$, plus a random error $\varepsilon$. The ordered logit model is defined by:

$$
\begin{aligned}
y_{i}^{*}=\beta^{\prime} x_{i}+\varepsilon_{i}, \text { where } \varepsilon_{i} \mid x_{i} \sim \operatorname{LOG}(0,1) i i d, \\
y_{i}=\left\{\begin{array}{l}
1 \text { if } \alpha_{0}<y_{i}^{*}<\alpha_{1}, \\
2 \text { if } \alpha_{1}<y_{i}^{*}<\alpha_{2}, \\
\vdots \\
J \text { if } \alpha_{J-1}<y_{i}^{*}<\alpha_{J},
\end{array}\right.
\end{aligned}
$$

In the ordered logit model, $y_{i}$ is the answer of the respondent about MSP. The $y_{i}{ }^{*}$ and $\alpha_{i}$ in the above equations can be interpreted:

$$
P\left(y_{i}=j \mid x_{i}\right)=P\left(\alpha_{j-1}<y_{i}^{*}<\alpha_{j} \mid x_{i}\right)
$$

Thus $y_{i}{ }^{*}$ can be seen as respondent $i$ 's MSP on a scale from $-\infty$ to $\infty$. The higher the $y_{i}^{*}$, the higher is the pain.

However, the partial effects of the independent variables on the probabilities are not synonymous to their coefficients in the ordered probability choice models as these approaches are non-linear and the model will consider as many marginal effects as the number of outcomes $=j$. Intuitively, the marginal effects assess the change in the probability $P\left(y_{i}=\right.$ $j \mid x_{i}$ ) when $x_{k}$ increases by a single unit. All in all, the marginal effects are propounded as

$$
\frac{\partial P\left(y_{i}=j \mid x_{i}\right)}{\partial x_{i}}=\beta\left(\varphi\left(\alpha_{j-1}-\beta^{\prime} x_{i}\right)-\varphi\left(\alpha_{j}-\beta^{\prime} x_{i}\right)\right)
$$

where $\varphi$ symbolises to the derivative of the standard logistic distribution in the case of ordered logit model.

The marginal effects will underscore the change in probability of being in each of the classifications with a unit increase in MSP. Therefore, the marginal effect of $P\left(y_{i} \leq\right.$ $\left.j \mid x_{i}\right)$ for $j=3$ can be construed as it captures the variation in the probability that an individual thinks the increase in MSP for a unit change in $x_{k}$. Its probability equals to equation:

$$
\frac{\partial P\left(y_{i} \leq j \mid x_{i}\right)}{\partial x_{i}}=-\beta \varphi\left(\alpha_{j}-\beta^{\prime} x_{i}\right)
$$

\section{Data Collection}

Out of the 2010 students requested to participate in the study, parental consent was obtained by 913 of them. 896 questionnaires were collected but due to incompleteness and bias $^{1}, 47$ questionnaires were discarded. The final sample size contains 849 questionnaires. Data were collected during a typical day at school so that actual schoolbag weight could be recorded. Height was measured to an accuracy of $0.5 \mathrm{~cm}$ using a meter rule, and standing height was measured with the student shoes to avoid reluctance in participation.

Body and schoolbag weight were measured with electronic balances with an accuracy of $\pm 0.1 \mathrm{~kg}$. To ensure reliability of the protocol, the weight measurements were taken on the same day and by the same investigator, and the average value out of three measurements was recorded. With this data, each student's BMI was estimated in $\mathrm{kg} / \mathrm{m} 2$, and the relative schoolbag weight was estimated as a percentage of student weight (\% of BW). The time spent in carrying school bags were recorded in minutes and it accounts only standing and walking positions. On completion of the questionnaires, the investigator gave a pen as a token to each student and the students were notified that they can withdraw from the survey at any stage of the study.

Table 3 presents the summary statistics for the data used in this paper. About $89 \%$ of the overall students interviewed have MSP. About 53\%, 51\%, 70\% and 60\% have LBP, UBP, SP and NP respectively, a 3-point Likert-scale has been used to construct MSP indices. The average age in the sample is 14.5 years and the sample are roughly divided into three categories i.e., boys (49\%), girls (23\%) and mixed (28\%) secondary schools. Most of the students are from rural regions, accounting for about $71 \%$ of the sample. About $70 \%$ of the parents possess at least a secondary level education. About $30.6 \%$ are from middle-income earners (Level 2 and Level 3 ) while $74.1 \%$ are strongly in favour of replacing some books with e-books. The majority of students (86.3\%) use backpack type of schoolbag relative to others (e.g., shoulder bag and hand bag). About $58 \%$ of the students take private tuition while the mean English score is 49.2 . The mean body mass index (BMI) is 20.3, revealing an average normal weight. Overall, students carry their bags for 55.02 minutes per day. Mean length of strap and weight of bag are $56.6 \mathrm{~cm}$ and $4.4 \mathrm{~kg}$. Finally, about $29 \%$ of students have excess bag weight.

\footnotetext{
${ }^{1}$ Some respondents reported figures such as Rs 25.00 with respect to Tuition fees. These values do not fit the actual context for private tuition A few bag weights were written as $2-5$ grams instead of kilograms and they were omitted. Any flawed or partial responses were excluded from the final dataset.
} 
Table 3. Description and Summary Statistics

\begin{tabular}{|c|c|c|c|c|c|}
\hline Variable & Description & Mean & Std. Dev. & Minimum & Maximum \\
\hline \multicolumn{6}{|l|}{ Dependent } \\
\hline overall & student with MSP & 0.886 & 0.318 & 0 & 1 \\
\hline lower & student with lower BP & 1.681 & 0.722 & 1 & 3 \\
\hline upper & student with upper BP & 1.678 & 0.737 & 1 & 3 \\
\hline shoulder & student with SP & 1.961 & 0.749 & 1 & 3 \\
\hline neck & student with NP & 1.795 & 0.745 & 1 & 3 \\
\hline \multicolumn{6}{|c|}{ Independent: } \\
\hline lage & natural log of age of students & 2.662 & 0.151 & 2.398 & 2.996 \\
\hline girls & student from girls' schools & 0.227 & 0.419 & 0 & 1 \\
\hline mixed & student from co-school & 0.285 & 0.452 & 0 & 1 \\
\hline urban & student from urban regions & 0.290 & 0.454 & 0 & 1 \\
\hline $\mathrm{p}$ & mother with at least primary education & 0.258 & 0.438 & 0 & 1 \\
\hline $\mathrm{s}$ & mother with at least secondary education & 0.567 & 0.496 & 0 & 1 \\
\hline $\mathrm{t}$ & mother with at least tertiary education & 0.120 & 0.325 & 0 & 1 \\
\hline p1 & father with at least primary education & 0.250 & 0.433 & 0 & 1 \\
\hline s1 & father with at least secondary education & 0.631 & 0.483 & 0 & 1 \\
\hline $\mathrm{t} 1$ & father with at least tertiary education & 0.072 & 0.258 & 0 & 1 \\
\hline y2 & total family income between Rs. $10,000-20,000$ & 0.309 & 0.462 & 0 & 1 \\
\hline y3 & total family income between Rs. $20,000-30,000$ & 0.153 & 0.360 & 0 & 1 \\
\hline y4 & total family income between Rs. $30,000-40,000$ & 0.153 & 0.360 & 0 & 1 \\
\hline y5 & total family income above Rs. 40,000 & 0.122 & 0.328 & 0 & 1 \\
\hline tablet & perception that books should be replaced by tablets & 4.536 & 0.945 & 1 & 5 \\
\hline $\mathrm{bp}$ & backpack schoolbag type & 0.863 & 0.344 & 0 & 1 \\
\hline tuition & student takes tuition & 0.572 & 0.518 & 0 & 5 \\
\hline lt3english & natural $\log$ of $3^{\text {rd }}$ term English score & 3.832 & 0.401 & 0.693 & 4.533 \\
\hline lbmi & natural log of body mass index & 2.976 & 0.242 & 2.174 & 4.163 \\
\hline carriage & duration of walking and standing with schoolbag & 55.021 & 48.472 & 0 & 280 \\
\hline llength & natural log of length of schoolbag's strap & 4.002 & 0.279 & 1.649 & 4.771 \\
\hline lweights & natural log ofweight of schoolbag & 1.353 & 0.549 & -0.693 & 2.797 \\
\hline excess & student with excess schoolbag weight & 0.291 & 0.454 & 0 & 1 \\
\hline
\end{tabular}

(Author's own calculations)

\section{RESULTS AND ANALYSIS FOR DETERMINANTS OF MUSCOSKELETAL PAINS}

The models display reasonable goodness-of-fit based on the pseudo- $\mathrm{R}^{2}$ and pass most of the diagnostic tests. These are primarily based on ordinary least squares (OLS) techniques. They include the variance inflation factor (VIF), the Breusch and Pagan (1979) and White (1980) heteroskedasticity tests, Jarque and Bera normality test (1987) and the omitted-variable bias regression equation specification error test (RESET) of DeBenedictis and Giles (1998). The VIF is found to be lower than 5 , and this implies no severe multicollinearity. A value of 5 or 10 indicates a multicollinearity problem (O’Brien, 2007). Heteroskedasticity is detected but does not cause bias or inconsistency estimators. As such, robust standard errors are computed. Although the normality assumption of residuals is rejected at the $1 \%$ significance level, asymptotic results can still hold for a wider class of distributions (Von CramonTaubadel, 1998). Only for the Overall MSP model, the diagnostic RESET statistics detect model misspecification and therefore results for the logit model should be interpreted with caution (David, 2007).

In the ordinary least squares approach, can be interpreted as the extent by which the endogenous variable, on average increases following a unit change in the independent variable. Due to the ordinal nature of the dependent variable, it is impractical to make substantial interpretations of the coefficients while using OLS, the use of marginal effects come into play. However, the partial effects of the independent variables on the probabilities are not synonymous to their coefficients in the ordered probability choice models as these approaches are non-linear and the model will entertain as many marginal effects as the number of outcomes $=j$. Intuitively, the marginal effects assess the change in the probability when increases by a single unit.

At first, an overall logistic regression model is used to examine pain occurrence, irrespective of the region. Since the pain was assessed in four separate regions, a different logistic regression model was applied to each region of pain. Therefore, a total of five models are run in addition to the calculation of marginal effects in each case. In each model, the input variables are age, gender, location, father education level, mother education level, total family income, perception about replacing some books with tablets, bag pack, tuition, performance, BMI, carriage, length of bag straps, weight and excess weight.

The brackets designate the p-values of the corresponding variables. Tables 4-8 show the results of the five different models namely overall MSP, LBP, UBP, SP and NP with various variables that are statistically significant in influencing student's pain in four secondary schools in Mauritius. Each table in turn consists of two models with normal weight and excess weight. The study analysed various determinants including socioeconomic characteristics, student perception 
Table 4. Ordered Logit Model for Overall Musculoskeletal Pains

\begin{tabular}{|c|c|c|c|c|}
\hline \multirow{2}{*}{ Variables } & \multicolumn{2}{|c|}{ Model 1} & \multicolumn{2}{|c|}{ Model 2} \\
\hline & Coefficient & Marginal Effects & Coefficient & Marginal Effects \\
\hline \multirow[t]{2}{*}{ lage } & 0.680 & 0.048 & 0.966 & 0.067 \\
\hline & $(0.972)$ & $(0.069)$ & (1.000) & $(0.070)$ \\
\hline \multirow[t]{2}{*}{ girls } & 2.452 & 0.115 & 2.569 & 0.116 \\
\hline & $(0.588)^{*}$ & $(0.017)^{*}$ & $(0.587)^{*}$ & $(0.016)^{*}$ \\
\hline \multirow[t]{2}{*}{ mixed } & 1.045 & 0.063 & 1.277 & 0.073 \\
\hline & $(0.399)^{*}$ & $(0.021)^{*}$ & $(0.405)^{*}$ & $(0.020) *$ \\
\hline \multirow[t]{2}{*}{ urban } & -0.238 & -0.018 & -0.297 & -0.028 \\
\hline & $(0.276)$ & $(0.021)$ & $(0.283)$ & $(0.022)$ \\
\hline \multirow[t]{2}{*}{$\mathrm{p}$} & -1.107 & -0.096 & -1.029 & -0.090 \\
\hline & $(0.716)$ & $(0.080)$ & $(0.707)$ & $(0.072)$ \\
\hline \multirow[t]{2}{*}{$\mathrm{s}$} & -1.034 & -0.071 & -0.965 & -0.065 \\
\hline & $(0.723)$ & $(0.050)$ & $(0.710)$ & $(0.047)$ \\
\hline \multirow[t]{2}{*}{$\mathrm{t}$} & -1.111 & -0.113 & -1.071 & -1.106 \\
\hline & $(0.781)$ & $(0.107)$ & $(0.777)$ & $(0.102)$ \\
\hline \multirow[t]{2}{*}{$\mathrm{p} 1$} & 0.897 & 0.054 & 1.047 & 0.060 \\
\hline & $(0.531)^{\ddagger}$ & $(0.027)^{+}$ & $(0.508)^{+}$ & $(0.024)^{+}$ \\
\hline \multirow[t]{2}{*}{ s1 } & 1.042 & 0.085 & 1.211 & 0.099 \\
\hline & $(0.496)^{+}$ & $(0.047)^{+}$ & $(0.477)^{*}$ & $(0.046)^{+}$ \\
\hline \multirow[t]{2}{*}{$\mathrm{t} 1$} & 1.779 & 0.071 & 2.046 & 0.074 \\
\hline & $(0.671)^{*}$ & $(0.016)^{*}$ & $(0.650)^{*}$ & $(0.014)^{*}$ \\
\hline \multirow{2}{*}{ y2 } & 0.178 & 0.012 & 0.225 & 0.015 \\
\hline & $(0.350)$ & $(0.024)$ & (0.353) & $(0.023)$ \\
\hline \multirow[t]{2}{*}{ y3 } & -0.086 & -0.006 & -0.056 & -0.004 \\
\hline & $(0.416)$ & $(0.031)$ & $(0.414)$ & $(0.030)$ \\
\hline \multirow[t]{2}{*}{$\mathrm{y} 4$} & -0.418 & -0.034 & -0.316 & -0.004 \\
\hline & $(0.427)$ & (0.039) & $(0.426)$ & $(0.030)$ \\
\hline \multirow[t]{2}{*}{ y5 } & -0.160 & -0.012 & -0.100 & -0.007 \\
\hline & (0.459) & $(0.036)$ & (0.463) & $(0.034)$ \\
\hline \multirow[t]{2}{*}{ tablet } & 0.309 & 0.022 & 0.322 & 0.022 \\
\hline & $(0.107)^{*}$ & $(0.008)^{*}$ & $(0.109)^{*}$ & $(0.007)^{*}$ \\
\hline $\mathrm{bp}$ & 0.005 & 0.0003 & 0.006 & 0.0004 \\
\hline & $(0.325)$ & $(0.023)$ & (0.326) & $(0.023)$ \\
\hline tuition & -0.268 & -0.019 & -0.261 & -0.018 \\
\hline & $(0.215)$ & $(0.015)$ & $(0.215)$ & $(0.015)$ \\
\hline lt3english & 0.993 & 0.070 & 0.984 & 0.068 \\
\hline & $(0.273)^{*}$ & $(0.019)^{*}$ & $(0.279)^{*}$ & $(0.020)^{*}$ \\
\hline lbmi & 0.264 & 0.019 & 1.019 & 0.071 \\
\hline & $(0.476)$ & $(0.034)$ & $(0.553)$ & $(0.039)$ \\
\hline carriage & 0.008 & 0.001 & 0.007 & 0.001 \\
\hline & $(0.003)^{+}$ & $(0.0002)^{+}$ & $(0.003)^{+}$ & $(0.0002)^{*}$ \\
\hline llengths & -0.007 & -0.001 & 0.063 & 0.004 \\
\hline & $(0.438)$ & $(0.031)$ & $(0.431)$ & (0.030) \\
\hline lweights & 0.573 & 0.041 & - & - \\
\hline & $(0.183)^{*}$ & $(0.013)^{*}$ & - & - \\
\hline excess & - & - & 1.003 & 0.060 \\
\hline & - & - & $(0.334)^{*}$ & $(0.017)^{*}$ \\
\hline Intercept & -7.095 & - & -10.235 & - \\
\hline & $(3.271)^{+}$ & - & $(3.490)^{*}$ & - \\
\hline$N$ & & & & \\
\hline Wald $\chi^{2}(22)$ & & $00]^{*}$ & & \\
\hline P Pseudo- $R^{2}$ & & & & \\
\hline VIF & & & & \\
\hline Breusch-Pagan & & $000]^{*}$ & & \\
\hline White & & 174] & & \\
\hline Jarque-Bera & & $000]^{*}$ & & \\
\hline Debenedictis-Giles & & $34]^{+}$ & & \\
\hline
\end{tabular}

The p-value is given in brackets. ${ }^{*},{ }^{++},{ }^{+}$and denote $1 \%, 5 \%$ and $10 \%$ significance level respectively.

(Author's own calculations)

of the use of tablets, type of schoolbag, private tuition, performance, duration of bag carriage and anthropometric characteristics are assessed.
The results are partly compared with those obtained by two studies (Papadopoulo et al., 2014; Springett \& Wise, 2007) which deal with the promotion of healthy backs and BPs. The ordered Logit is the best modelling as far as Likert type scale is concerned as demonstrated (Greene, 2000). Two models are 
considered with the weight of bags and excess weight included as separate explanatory variables. Spearman correlation between the variables accounts for 0.56. Factors like age, location, backpack and the length of straps do not significantly impact overall MSP supporting the findings of Dianat et al. (2013), AL-Qato (2012), Natasha et al. (2018), and Yoon (2014) respectively. Only the significant variables that explain overall MSP are discussed below.

\section{Models for Overall MSP}

From Table 4, the logistic regression reveals that gender, mother's education level, the perception of replacing books with tablets, English language performance and bag weights are explanatory variables of overall body MSP. The $\mathrm{R}^{2}$ for the total is found to be around 0.14. It demonstrates that the model is relatively satisfying since it is between 0 and 1 . For $\mathrm{R}^{2}$ to rise, there should be an increase in sample size.

\section{Gender and overall MSP}

Regarding gender, girls' more than boys are significantly more likely $(p<0.01)$ to experience overall MSP. The results for gender and its association with pain is by literature whereby females are more likely to experience pain compared to males (Bailey, 2009; Fillingim, 2003; Leveille et al., 2001; Wáng et al., 2016). The marginal effects in Models 1 and 2 suggest that an increase in the number of girl's students' in schools is associated with around $16 \%-17 \%$ more likely to experience the presence of pain. A similar effect is seen even in mixed schools as it is composed of girls and boys who may be related to the female composition as it is suggested that females diagnose, state and report their symptoms more sensitively than males (Rajan \& Koti, 2013; Siivola, 2003).

\section{Mother's education level and overall MSP}

An increase in mother's education level causes an increase in student's MSP and tertiary education is the most significant $(p<0.01)$. The marginal effects indicate that an increase in mother's tertiary education level is linked to around2\% more likely MSP in students. For the question of parental literacy level, the results indicate mother's education levels have more significant impacts on pains in general compared to father's education levels consistent with a recent finding (El-Nagar \& Mady, 2017).

\section{Tablet's (e-book) and overall MSP}

The student's perception of replacing books with tablets has a significant positive impact on MSP implying that students having MSP are more likely to opt for tablets. Such a perception matches with literature where carrying e-textbooks on a lightweight device is better than being burdened with the added weight of paper-based books (Zimerman, 2011).

\section{Performance and overall MSP}

English performance is positively and significantly linked with MSP, and marginal indicates that an increase in performance is associated with about $2 \%$ more likely MSP in students. The result tallies another study which whereby performance is linked to overall body pains (Sampaio et al., 2016). A possible explanation for such pains is academic pressure and psychological pressure about the approaching exams and the reduction of physical activity caused by the academic burden (Shan et al., 2013).

\section{Duration of bag carriage and overall MSP}

The duration of school bag carriage positively impacts MSP $(p<0.05)$. It is likely that the risk factors for musculoskeletal agony are connected with the duration of school bag carriage combined with effects of heavy loads, load shape, size and location of the load on the body (Chansirinukor et al., 2001; Mwaka et al., 2014).

\section{Bag weights and overall MSP}

Bag weights relative to body weight positively affect MSP, and it increases as weight increases. From Table 1, the marginal effects in models 1 and 2 indicate that an increase in the weight of bags is associated with around $1 \%$ more likely to experience overall pain with normal weight and around $2 \%$ more likely pain with an increase of excess weight. In this study overall pains are observed even below $10 \%$ of body weight and the intensity of pains increases linearly with excess $\%$ body weight as illustrated in many independent researchers (Hong \& Cheung et al., 2003; Pascoe et al., 1997; Paušić et al., 2013; Walicka-Cupry et al., 2015).

\section{Models for LBP}

From Table 5, the logistic regression in model 2 reveals that gender, parent's education level, highest income level, backpack and duration of bag carriage are explanatory variables of LBP. The $\mathrm{R}^{2}$ for LBP is found to be 0.036 . For $\mathrm{R}^{2}$ to rise, there should be an increase in sample size. The BreuschPagan test statistic has a p-value below an appropriate threshold $(\mathrm{p}<0.01)$ thus the null hypothesis of homoskedasticity is rejected, and heteroskedasticity assumed.

\section{Gender and $L B P$}

The girls' variable under dimension gender is significantly more likely $(p<0.05)$ to experience LBP than boys. The results for gender and its association with LBP is in line with literature whereby dorsal pains and LBP is more likely in girls of age 14 than boys of the same cohort (Kedra \& Czaprowski, 2013; Walicka-Cupry, 2004). From Table 5, the marginal effects in Models 1 and 2 suggest that an increase in the number of girl's students in schools is associated with around $11 \%$ less likely not to experience LBP and 5\% more likely to sometimes get pains and $6 \%$ more likely to always get pains. An increase in the number of mixed students in schools is associated with around $20 \%$ less likely not to experience LBP and 9\% more likely to sometimes get pain and $11 \%$ more likely to always get pain.

\section{Parent's education level and $L B P$}

In general, both Models indicate negative coefficients between mother education and LBP. Students having educated mothers are less likely to experience LBP, and this is in line with, Leboeuf-Yde et al. (2002) who find a modest negative association can exist between parental education and LBP in young students. Hestbaek et al. (2008) approve that low parental educational is an indicator of the socio-economic status of the family and is associated with lower back pain (LBP) in children and adolescents. Mikkonen (2015) reveals that socio-economic status is not reliably linked to LBP, but 
Table 5. Ordered Logic Model for Lower Back Pains

\begin{tabular}{|c|c|c|c|c|c|c|c|c|}
\hline \multirow{2}{*}{ Variables } & \multicolumn{4}{|c|}{ Model 1} & \multicolumn{4}{|c|}{ Model 2} \\
\hline & Coeff. & ME 1 & ME 2 & ME 3 & Coeff. & ME 1 & ME 2 & ME 3 \\
\hline \multirow{2}{*}{ lage } & -0.070 & 0.016 & -0.008 & -0.009 & -0.0004 & 0.0001 & -0.0001 & -0.0001 \\
\hline & $(0.569)$ & (0.133) & $(0.062)$ & $(0.071)$ & $(0.572)$ & $(0.134)$ & $(0.062)$ & $(0.071)$ \\
\hline \multirow{2}{*}{ girls } & 0.479 & -0.112 & 0.052 & 0.059 & 0.470 & -0.110 & 0.051 & 0.059 \\
\hline & $(0.222)^{+}$ & $(0.051)^{+}$ & $(0.024)^{+}$ & $(0.028)^{+}$ & $(0.218)^{+}$ & $(0.050)^{+}$ & $(0.023)^{+}$ & $(0.028)^{+}$ \\
\hline \multirow{2}{*}{ mixed } & 0.846 & -0.199 & 0.093 & 0.106 & 0.842 & -0.197 & 0.092 & 0.105 \\
\hline & $(0.243)^{*}$ & $(0.055)^{*}$ & $(0.026)^{*}$ & $(0.031)^{*}$ & $(0.235)^{*}$ & $(0.053)^{*}$ & $(0.025)^{*}$ & $(0.030)^{*}$ \\
\hline \multirow{2}{*}{ urban } & -0.057 & 0.013 & -0.006 & -0.007 & -0.065 & 0.015 & -0.007 & -0.008 \\
\hline & $(0.157)$ & $(0.037)$ & $(0.017)$ & $(0.020)$ & $(0.158)$ & $(0.037)$ & $(0.017)$ & $(0.020)$ \\
\hline \multirow[b]{2}{*}{$\mathrm{p}$} & -0.715 & 0.167 & -0.078 & -0.089 & -0.718 & 0.167 & -0.078 & -0.089 \\
\hline & $(0.327)^{+}$ & $(0.076)^{+}$ & $(0.036)^{+}$ & $(0.040)^{+}$ & $(0.327)^{+}$ & $(0.076)^{+}$ & $(0.036)^{+}$ & $(0.040)^{+}$ \\
\hline \multirow[b]{2}{*}{$\mathrm{S}$} & -0.541 & 0.126 & -0.059 & -0.067 & -0.540 & 0.126 & -0.059 & -0.067 \\
\hline & $(0.314)^{\ddagger}$ & $(0.073)^{\ddagger}$ & $(0.035)^{\ddagger}$ & $(0.039)^{\ddagger}$ & $(0.313)^{\ddagger}$ & $(0.073)^{\ddagger}$ & $(0.035)^{\ddagger}$ & $(0.039)^{\ddagger}$ \\
\hline \multirow[b]{2}{*}{$\mathrm{t}$} & -0.710 & 0.166 & -0.078 & -0.088 & -0.709 & 0.166 & -0.076 & -0.088 \\
\hline & $(0.378)^{\ddagger}$ & $(0.088)^{\ddagger}$ & $(0.042)^{\ddagger}$ & $(0.047)^{\ddagger}$ & $(0.377)^{\ddagger}$ & $(0.088)^{\ddagger}$ & $(0.042)^{\ddagger}$ & $(0.047)^{\ddagger}$ \\
\hline \multirow{2}{*}{$\mathrm{p} 1$} & -0.108 & 0.025 & -0.012 & -0.013 & -0.099 & 0.023 & -0.011 & -0.012 \\
\hline & $(0.390)$ & $(0.091)$ & $(0.043)$ & $(0.049)$ & $(0.390)$ & $(0.091)$ & $(0.043)$ & (0.049) \\
\hline \multirow{2}{*}{ s1 } & -0.135 & 0.032 & -0.015 & -0.017 & -0.128 & 0.030 & -0.014 & -0.016 \\
\hline & $(0.375)$ & $(0.088)$ & $(0.041)^{+}$ & $(0.047)$ & $(0.375)$ & (0.088) & $(0.041)$ & $(0.047)$ \\
\hline \multirow{2}{*}{$\mathrm{t} 1$} & 0.756 & -0.177 & 0.083 & 0.094 & 0.772 & -0.181 & 0.084 & 0.096 \\
\hline & $(0.440)^{\ddagger}$ & $(0.102)^{\ddagger}$ & $(0.048)^{\ddagger}$ & $(0.055)^{\ddagger}$ & $(0.440)^{\ddagger}$ & $(0.102)^{\ddagger}$ & $(0.048)^{\ddagger}$ & $(0.055)^{\ddagger}$ \\
\hline \multirow{2}{*}{ y2 } & -0.158 & 0.037 & -0.017 & -0.020 & -0.149 & 0.035 & -0.016 & -0.018 \\
\hline & (0.193) & $(0.045)$ & $(0.021)$ & $(0.024)$ & $(0.195)$ & $(0.046)$ & $(0.021)$ & $(0.024)$ \\
\hline \multirow{2}{*}{ y3 } & -0.190 & 0.045 & -0.021 & -0.024 & -0.185 & 0.043 & -0.020 & -0.023 \\
\hline & $(0.238)$ & $(0.056)$ & $(0.026)$ & $(0.030)$ & $(0.238)$ & $(0.056)$ & $(0.026)$ & $(0.030)$ \\
\hline \multirow{2}{*}{$\mathrm{y} 4$} & -0.337 & 0.080 & -0.037 & -0.042 & -0.323 & 0.076 & -0.035 & -0.040 \\
\hline & $(0.237)$ & $(0.055)$ & $(0.026)$ & $(0.030)$ & (0.239) & $(0.056)$ & $(0.026)$ & $(0.030)$ \\
\hline \multirow{2}{*}{ y5 } & -0.595 & 0.139 & -0.065 & -0.074 & -0.581 & 0.136 & -0.064 & -0.072 \\
\hline & $(0.274)^{+}$ & $(0.064)^{+}$ & $(0.030)^{+}$ & $(0.034)^{+}$ & $(0.275)^{+}$ & $(0.064)^{+}$ & $(0.030)^{+}$ & $(0.035)^{+}$ \\
\hline tablet & -0.034 & 0.008 & -0.004 & -0.004 & -0.033 & 0.008 & -0.004 & -0.004 \\
\hline tablet & $(0.078)$ & (0.018) & (0.009) & $(0.010)$ & $(0.078)$ & $(0.018)$ & (0.009) & $(0.010)$ \\
\hline $\mathrm{hn}$ & -0.496 & 0.116 & -0.054 & -0.062 & -0.503 & 0.118 & -0.055 & -0.063 \\
\hline $\mathrm{Dp}$ & $(0.191)^{*}$ & $(0.044)^{*}$ & $(0.021)^{*}$ & $(0.024)^{*}$ & $(0.191)^{*}$ & $(0.044) *$ & $(0.021)^{*}$ & $(0.024)^{*}$ \\
\hline tuition & 0.051 & -0.012 & 0.006 & 0.006 & 0.055 & -0.013 & 0.006 & 0.007 \\
\hline tuition & $(0.158)$ & $(0.037)$ & $(0.017)$ & $(0.020)$ & $(0.157)$ & $(0.037)$ & $(0.017)$ & $(0.020)$ \\
\hline & 0.130 & -0.030 & 0.014 & 0.016 & 0.118 & -0.028 & 0.013 & 0.015 \\
\hline It3english & $(0.220)$ & $(0.051)$ & $(0.024)$ & $(0.027)$ & $(0.221)$ & $(0.052)$ & $(0.024)$ & $(0.027)$ \\
\hline lhmi & 0.134 & -0.031 & 0.015 & 0.017 & 0.206 & -0.048 & 0.022 & 0.026 \\
\hline Ibm1 & $(0.297)$ & $(0.051)$ & $(0.032)$ & $(0.037)$ & $(0.324)$ & $(0.076)$ & $(0.035)$ & $(0.040)$ \\
\hline & 0.005 & -0.001 & 0.001 & 0.001 & 0.005 & -0.001 & 0.001 & 0.001 \\
\hline carriage & $(0.001)^{*}$ & $(0.0003)^{*}$ & $(0.0001)^{*}$ & $(0.0002)^{*}$ & $(0.001)^{*}$ & $(0.0003)^{*}$ & $(0.0001)^{*}$ & $(0.0002)^{*}$ \\
\hline llenoths & 0.052 & -0.012 & 0.006 & 0.007 & 0.047 & -0.011 & 0.005 & 0.006 \\
\hline llengtns & $(0.336)$ & $(0.078)$ & $(0.037)$ & $(0.042)$ & $(0.334)$ & $(0.078)$ & $(0.037)$ & $(0.042)$ \\
\hline lyoights & 0.000 & 0.0001 & 0.00003 & 0.00004 & - & - & - & - \\
\hline Iweignts & (0.129) & $(0.030)$ & $(0.014)$ & $(0.016)$ & - & - & - & - \\
\hline & - & - & - & - & 0.105 & -0.025 & 0.011 & 0.013 \\
\hline excess & - & - & - & - & $(0.169)$ & $(0.040)$ & $(0.019)$ & $(0.021)$ \\
\hline$N$ & & & & & & & & \\
\hline Wald $\chi^{2}(22)$ & & 59.5 & $000]^{*}$ & & & 60.00 & $00]^{*}$ & \\
\hline P Pseudo- $R^{2}$ & & & & & & & & \\
\hline VIF & & & & & & & & \\
\hline Breusch-Pagan & & 8.68 & $03]^{*}$ & & & 8.27 & $4]^{*}$ & \\
\hline White & & 245.7 & $.511]$ & & & 241.7 & $565]$ & \\
\hline Jarque-Bera & & 104.1 & $000]^{*}$ & & & 103.66 & $000]^{*}$ & \\
\hline Debenedictis-Giles & & 1.10 & 357] & & & 1.043 & 396] & \\
\hline
\end{tabular}

The p-value is given in brackets. ${ }^{*},{ }^{++},{ }^{+}$and denote $1 \%, 5 \%$ and $10 \%$ significance level respectively.

(Author's own calculations)

clusters of problems may favour LBP. In a review, parental education significantly impacts chronic pains (King et al., 2011; Kumar et al., 2017). From Table 5, the marginal effects in Models 1 and 2 suggest that an increase in mother's education level is associated with around $16 \%$ more likely not to experience LBP and $8 \%$ more likely to sometimes get pain and 9\% more likely to always get pain. A mild positive association is seen between father's tertiary education level and LBP which is in contrary to research where LBP is isolated in girl students who help their fathers in farming after school hour (Mikkonen et al., 2016). The educated fathers might be 
encouraging extra hard work related to studies after school which is common in Mauritius.

\section{Highest income level and LBP}

Both Models assert negative impacts of highest income level on the occurrence of LBP in students. According to Issa et al. (2016) small family members and high family monthly income provide ingredients to inhibit LBP. The marginal effects in both models advocate that an increase in parent's highest income level is negatively associated with around $14 \%$ more likely not to experience LBP and 7\% less likely to sometimes get pain and $7 \%$ less likely to always get pain.

\section{Back pack and LBP}

The results in both models give negative association $(\mathrm{p}<$ 0.01 ) between the use of backpacks to carry bags and the incident of LBP. It goes against the findings of Natasha et al. (2018) that indicate no association between the use of a backpack and the occurrence of LBP. The marginal effects in both models support that an increase in the use of backpack is negatively associated with around $12 \%$ more likely not to experience LBP and 5\% less likely to sometimes get pain and $6 \%$ less likely to always get pain. It may be due to the way and mode in which the backpack is carried (Candotti et al., 2012; Fernandes et al., 2008; Melo-Marins, 2015).

\section{Duration of bag carriage and LBP}

The DBC is positively linked to the event of LBP in students and an increase in the length of time will have a minor impact on LBP. The duration of bag carriage by students is positively associated $(p<0.01)$ with LBP occurrence. This outcome is in line with other research stating that a longer duration of carrying a school bag may increase the risk of adolescent BP (Aundhakar et al., 2015; Grimmer \& Williams 2000; Paušić et al., 2013). The marginal effects in models 1 and 2 suggest that an increase in the use of backpack is linked with significant changes in the feeling of LBP. Hong and Fong (2008) find no significant association between the DBC and LBP. It is essential to take into consideration many factors like speed, type of terrain among others while measuring its impact on LBP (Perrone et al., 2018).

\section{Models for UBP}

The logistic regression (model 3) in Table 6 reveals that gender, the perception of replacing books with tablets and duration of bag carriage are explanatory variables of UBP. The $\mathrm{R}^{2}$ for UBP is found to be around 0.028. It demonstrates that the model is relatively satisfying since it is between 0 and 1 . For $\mathrm{R}^{2}$ to rise, there should be an increase in sample size.

\section{Gender and UBP}

For gender, mixed students are significantly more likely ( $p$ $<0.01)$ to experience UBP than boys. This result may be due to female students being more susceptible to BP (Kellis \& Emmanouilidou, 2010) due to their relatively weaker physical strength. Females are more likely to help their family at home for daily chores as a study by Mikkonen et al. (2016) reveals that some female students even help for farming after school hours. The marginal effects in models 1 and 2 suggest that an increase in the number of mixed students in schools is associated with around 20\% less likely to experience UBP and
9\% more likely to sometimes get pain and $11 \%$ more likely to always get UBP.

\section{Tablet's (e-book) and UBP}

Table 6 reveals that regarding the perception about replacing some books with tablets, there is a significant impact $(\mathrm{p}<0.1)$ to experience UBP. Thus, students having UBP are more likely to go with this change. Such behaviour is linked to the results of some studies suggesting that heavily loaded backpacks laden with textbooks can cause various back and health problems (Embong et al., 2012; Van Heerden \& Van Belle, 2013). From Table 6, the marginal effects in models 1 and 2 suggest that an increase in such perception has a significant impact on the different levels of UBP.

\section{Duration of bag carriage and UBP}

The duration of bag carriage by students is positively associated $(\mathrm{p}<0.05)$ with UBP occurrence in both models. This outcome is in line with other research stating that a longer duration of carrying a school bag may increase the risk of adolescent BP (Aundhakar et al., 2015; Grimmer \& Williams, 2000; Paušić et al., 2013). The marginal effects in models 1and 2 suggest that an increase in the duration of bag carriage is associated with significant small changes in the feeling of UBP.

\section{Models for SP}

The logistic regression (Model 4) in Table 7 reveals that gender, backpack, the duration of bag carriage and weights of bags are explanatory variables of SP. The $\mathrm{R}^{2}$ for SP is found to be around 0.04 . It asserts that the model is relatively satisfying since it is between 0 and 1 . For $\mathrm{R}^{2}$ to rise, there should be an increase in sample size.

\section{Gender and SP}

For gender, mixed students are significantly more likely ( $p$ $<0.01$ ) to experience SP than boys. These findings are tallying with literature whereby the occurrence of SP and NP and low back complaints are more common in females than males (Dianat et al., 2014; Mikklesson et al., 1997). From Table 7, the marginal effects in models 1 and 2 suggest that an increase in the number of girl students in schools is associated with around $16 \%$ less likely not to experience SP and 15\% more likely to always get SP. The marginal effects are almost the same for mixed students due to the presence of the female characteristics. According to Yeun (2017) neck pain (NP) and shoulder pain (SP) are linked to gender, mainly in women.

\section{Backpack and SP}

The use of a backpack on both shoulders relative to shoulder bag and handbags is negatively connected to SP. This indicates that Mauritian students have a good practice of using backpacks in contrast to SPs associated asymmetrical distribution of backpack load in students (Yoon, 2014). Accordingly, carrying backpack relative to others, shoulder bag and handbag is associated with NP and SP supported by other investigations (Dianat et al., 2014; Freedman, 2009). From Table 4, the marginal effects in models 1 and 2 suggest that an increase in the use of backpack by students in schools is associated with around $8 \%$ more likely not to experience SP and about $7 \%$ less likely to always get SP. BMI is positively associated with SP only in model 2 with a marginal effect 
Table 6. Ordered Logic Model for Upper Back Pains

\begin{tabular}{|c|c|c|c|c|c|c|c|c|}
\hline \multirow{2}{*}{ Variables } & \multicolumn{4}{|c|}{ Model 1} & \multicolumn{4}{|c|}{ Model 2} \\
\hline & Coeff. & ME 1 & ME 2 & ME 3 & Coeff. & ME 1 & ME 2 & ME 3 \\
\hline \multirow{2}{*}{ lage } & 0.264 & -0.063 & 0.028 & 0.035 & 0.320 & -0.076 & 0.034 & \\
\hline & $(0.554)$ & $(0.132)$ & $(0.059)$ & $(0.073)$ & $(0.560)$ & $(0.133)$ & $(0.059)$ & 0.042 \\
\hline \multirow{2}{*}{ girls } & 0.232 & -0.057 & 0.025 & 0.032 & 0.265 & -0.063 & 0.028 & (0.074) \\
\hline & $(0.216)$ & $(0.051)$ & $(0.023)$ & $(0.029)$ & $(0.213)$ & $(0.050)$ & $(0.022)$ & 0.035 \\
\hline \multirow{2}{*}{ mixed } & 0.836 & -0.198 & 0.088 & 0.110 & 0.891 & -0.212 & 0.094 & $(0.028)$ \\
\hline & $(0.240)^{*}$ & $(0.055)^{*}$ & $(0.025)^{*}$ & $(0.032)^{*}$ & $(0.230)^{*}$ & $(0.053)^{*}$ & $(0.024)^{*}$ & 0.111 \\
\hline \multirow{2}{*}{ urban } & -0.047 & 0.011 & -0.005 & -0.006 & -0.053 & 0.013 & -0.006 & $\begin{array}{c}(0.031)^{*} \\
-0.616(0.020)\end{array}$ \\
\hline & $(0.153)$ & $(0.036)$ & $(0.016)$ & $(0.020)$ & $(0.153)$ & $(0.036)$ & $(0.016)$ & $-0.016(0.020)$ \\
\hline \multirow[b]{2}{*}{$\mathrm{p}$} & 0.097 & -0.023 & 0.010 & 0.013 & 0.122 & -0.030 & 0.013 & 0.016 \\
\hline & $(0.356)$ & $(0.085)$ & $(0.038)$ & $(0.047)$ & $(0.350)$ & $(0.083)$ & $(0.037)$ & $\begin{array}{c}(0.046) \\
0.035\end{array}$ \\
\hline \multirow{2}{*}{$\mathrm{S}$} & 0.249 & -0.057 & 0.025 & 0.032 & 0.269 & -0.064 & 0.028 & 0.035 \\
\hline & $(0.349)$ & $(0.083)$ & $(0.037)$ & $(0.046)$ & $(0.342)$ & $(0.081)$ & $(0.036)$ & (0.045) \\
\hline \multirow{2}{*}{$\mathrm{t}$} & -0.360 & 0.090 & -0.040 & -0.050 & -0.363 & 0.086 & -0.038 & -0.048 \\
\hline & $(0.413)$ & $(0.098)$ & $(0.043)$ & $(0.054)$ & (0.409) & $(0.097)$ & $(0.043)$ & (0.054) \\
\hline \multirow{2}{*}{$\mathrm{p} 1$} & 0.150 & -0.036 & 0.016 & 0.020 & 0.173 & -0.041 & 0.018 & $\begin{array}{c}0.023 \\
(0.057)\end{array}$ \\
\hline & (0.439) & $(0.104)$ & $(0.046)$ & $(0.058)$ & $(0.435)$ & $(0.103)$ & $(0.046)$ & (0.057) \\
\hline \multirow{2}{*}{ s1 } & 0.223 & -0.053 & 0.023 & 0.029 & 0.240 & -0.057 & 0.025 & 0.032 \\
\hline & $(0.424)$ & (0.101) & $(0.045)$ & $(0.056)$ & $(0.421)$ & $(0.100)$ & $(0.045)$ & (0.055) \\
\hline \multirow{2}{*}{$\mathrm{t} 1$} & 0.630 & -0.150 & 0.066 & 0.083 & 0.668 & -0.159 & 0.071 & 0.088 \\
\hline & $(0.503)$ & (0.119) & $(0.053)$ & $(0.066)$ & $(0.502)$ & (0.118) & $(0.053)$ & (U.066) \\
\hline \multirow{2}{*}{ y2 } & -0.150 & 0.035 & -0.016 & -0.020 & -0.141 & 0.033 & -0.015 & $\begin{array}{l}-0.019 \\
0.026\end{array}$ \\
\hline & $(0.194)$ & $(0.046)$ & $(0.020)$ & $(0.026)$ & $(0.194)$ & $(0.046)$ & $(0.020)$ & (0.026) \\
\hline \multirow{2}{*}{ y3 } & -0.043 & 0.010 & -0.005 & -0.006 & -0.038 & 0.009 & -0.004 & $\begin{array}{l}-0.005 \\
(0.030)\end{array}$ \\
\hline & $(0.227)$ & $(0.054)$ & $(0.024)$ & $(0.030)$ & $(0.227)$ & $(0.054)$ & $(0.030)$ & (U.05U) \\
\hline \multirow{2}{*}{$\mathrm{y} 4$} & -0.305 & 0.072 & -0.032 & -0.040 & -0.286 & 0.068 & -0.025 & $\begin{array}{c}-0.050 \\
(0.031\end{array}$ \\
\hline & $(0.236)$ & $(0.056)$ & $(0.025)$ & $(0.031)$ & $(0.238)$ & $(0.056)$ & $(0.025)$ & (0.031) \\
\hline \multirow{2}{*}{ y5 } & -0.398 & 0.094 & -0.042 & -0.052 & -0.380 & 0.090 & -0.040 & $\begin{array}{l}-0.050 \\
0.035\end{array}$ \\
\hline & $(0.268)$ & $(0.063)$ & $(0.028)$ & $(0.035)$ & $(0.268)$ & (0.063) & $(0.028)$ & (0.055) \\
\hline tohlet & 0.135 & -0.032 & 0.014 & 0.018 & 0.136 & -0.032 & 0.014 & 0.018 \\
\hline Ladiet & $(0.078)^{\ddagger}$ & $(0.018)^{\ddagger}$ & $(0.008)^{\ddagger}$ & $(0.010)^{\ddagger}$ & $(0.078)^{\ddagger}$ & $(0.018)^{\ddagger}$ & $(0.008)^{\ddagger}$ & (U.010) \\
\hline $\mathrm{hn}$ & -0.005 & 0.001 & -0.001 & -0.001 & -0.006 & 0.001 & -0.001 & $\begin{array}{l}-0.001 \\
(0.027)\end{array}$ \\
\hline & $(0.208)$ & (0.049) & $(0.022)$ & $(0.027)$ & (0.207) & (0.049) & $(0.022)$ & (U.027) \\
\hline tulition & -0.023 & 0.005 & -0.002 & -0.003 & -0.017 & 0.004 & -0.002 & $\begin{array}{l}-0.002 \\
(0.019)\end{array}$ \\
\hline tuition & $(0.147)$ & $(0.035)$ & $(0.015)$ & $(0.019)$ & $(0.148)$ & $(0.035)$ & $(0.016)$ & (0.019) \\
\hline lt3enolich & 0.219 & -0.052 & 0.023 & 0.029 & 0.217 & -0.050 & 0.023 & $\begin{array}{l}0.029 \\
(0.028)\end{array}$ \\
\hline It3engilsh & $(0.211)$ & $(0.050)$ & $(0.022)$ & $(0.028)$ & $(0.211)$ & $(0.050)$ & $(0.022)$ & $\begin{array}{l}(0.028) \\
0.042\end{array}$ \\
\hline lhmi & 0.111 & -0.026 & 0.012 & 0.015 & 0.318 & -0.100 & 0.034 & 0.042 \\
\hline lbmi & $(0.304)$ & $(0.072)$ & $(0.032)$ & $(0.040)$ & $(0.331)$ & $(0.069)$ & $(0.035)$ & $\begin{array}{l}(0.044) \\
0.0004\end{array}$ \\
\hline carriage & 0.003 & -0.001 & 0.0003 & 0.0004 & 0.003 & -0.001 & 0.0003 & $\begin{array}{c}0.0004 \\
(0.0002)^{+}\end{array}$ \\
\hline carriage & $(0.001)^{+}$ & $(0.0003)^{+}$ & $(0.0001)^{+}$ & $(0.000)^{+}$ & $(0.001)^{+}$ & $(0.0003)^{+}$ & $(0.0001)^{+}$ & $\begin{array}{c}(0.0002) \\
0.047\end{array}$ \\
\hline llenoths & 0.349 & -0.083 & 0.037 & 0.046 & 0.360 & -0.085 & 0.038 & 0.047 \\
\hline llengths & $(0.379)$ & $(0.090)$ & $(0.040)$ & $(0.050)$ & $(0.373)$ & $(0.088)$ & $(0.039)$ & $(0.049)$ \\
\hline lyoights & 0.186 & -0.044 & 0.020 & 0.025 & - & - & - & - \\
\hline iweignts & $(0.134)$ & $(0.032)$ & $(0.014)$ & $(0.018)$ & - & - & - & 0033 \\
\hline excess & - & - & - & - & 0.248 & -0.060 & 0.026 & $\begin{array}{c}0.033 \\
(0.023)\end{array}$ \\
\hline excess & - & - & - & - & $(0.172)$ & $(0.041)$ & $(0.018)$ & (0.023) \\
\hline$N$ & & & & & & & & \\
\hline Wald $\chi^{2}(22)$ & & 44.2 & $.003]^{*}$ & & & 43.8 & $04]^{*}$ & \\
\hline P Pseudo- $R^{2}$ & & & & & & & & \\
\hline VIF & & & & & & & & \\
\hline Breusch-Pagan & & 2.3 & 129] & & & 2.35 & 26] & \\
\hline White & & 292 & $.025]$ & & & 290.5 & $027]^{+}$ & \\
\hline Jarque-Bera & & 107. & $.000]^{*}$ & & & 108.2 & $000]^{*}$ & \\
\hline Debenedictis-Giles & & 1.38 & $.217]$ & & & 1.57 & 152] & \\
\hline
\end{tabular}

The p-value is given in brackets. ${ }^{*},{ }^{++},{ }^{+}$and denote $1 \%, 5 \%$ and $10 \%$ significance level respectively.

(Author's own calculations)

showing that an increase in BMI is $10 \%$ less likely not to feel pain at all.

\section{Duration of bag carriage and SP}

The duration of bag carriage by students has a weak positive association $(p<0.1)$ with SP occurrence in both models. This outcome is in line with other researchers stating that a longer duration of carrying a school bag may increase SP, but the combined effects of bag position and load cannot be dissociated (Chen \& Mu, 2018; Dockrell et al., 2015). The marginal effects in models 1 and 2 suggest that an increase in 
Table 7. Ordered Logit Model for Shoulder Pains

\begin{tabular}{|c|c|c|c|c|c|c|c|c|}
\hline \multirow{2}{*}{ Variables } & \multicolumn{4}{|c|}{ Model 1} & \multicolumn{4}{|c|}{ Model 2} \\
\hline & Coeff. & ME 1 & ME 2 & ME 3 & Coeff. & ME 1 & ME 2 & ME 3 \\
\hline \multirow{2}{*}{ lage } & -0.809 & 0.159 & -0.011 & -0.148 & -0.706 & 0.139 & -0.010 & -0.130 \\
\hline & $(0.556)$ & (0.109) & $(0.010)$ & $(0.102)$ & $(0.558)$ & (0.109) & $(0.010)$ & $(0.102)$ \\
\hline \multirow{2}{*}{ girls } & 0.804 & -0.158 & 0.011 & 0.147 & 0.837 & -0.165 & 0.012 & 0.153 \\
\hline & $(0.232)^{*}$ & $(0.045)^{*}$ & $(0.008)$ & $(0.043)^{*}$ & $(0.230)^{*}$ & $(0.044)^{*}$ & $(0.008)$ & $(0.042)^{*}$ \\
\hline \multirow{2}{*}{ mixed } & 0.763 & -0.150 & 0.011 & 0.140 & 0.827 & -0.163 & 0.012 & 0.151 \\
\hline & $(0.224)^{*}$ & $(0.043)^{*}$ & $(0.008)$ & $(0.041)^{*}$ & $(0.221)^{*}$ & $(0.042)^{*}$ & $(0.008)$ & $(0.040)^{*}$ \\
\hline \multirow{2}{*}{ urban } & -0.200 & 0.039 & -0.003 & -0.037 & -0.214 & 0.042 & -0.003 & -0.039 \\
\hline & $(0.145)$ & $(0.028)$ & $(0.003)$ & $(0.027)$ & $(0.145)$ & $(0.028)$ & $(0.003)$ & $(0.027)$ \\
\hline \multirow[b]{2}{*}{$\mathrm{p}$} & -0.089 & 0.018 & -0.001 & -0.016 & -0.063 & 0.012 & -0.001 & -0.012 \\
\hline & $(0.362)$ & $(0.071)$ & $(0.005)$ & $(0.066)$ & (0.359) & $(0.071)$ & $(0.005)$ & $(0.065)$ \\
\hline \multirow{2}{*}{$\mathrm{s}$} & -0.186 & 0.037 & -0.003 & -0.034 & -0.148 & 0.029 & -0.002 & -0.030 \\
\hline & $(0.361)$ & $(0.071)$ & $(0.005)$ & $(0.066)$ & $(0.357)$ & $(0.070)$ & $(0.005)$ & $(0.065)$ \\
\hline \multirow{2}{*}{$\mathrm{t}$} & -0.326 & 0.064 & -0.006 & -0.060 & -0.304 & 0.060 & -0.004 & -0.055 \\
\hline & $(0.416)$ & $(0.082)$ & $(0.007)$ & $(0.076)$ & $(0.412)$ & $(0.081)$ & $(0.007)$ & $(0.075)$ \\
\hline \multirow{2}{*}{ p1 } & 0.296 & -0.058 & 0.004 & 0.054 & 0.339 & -0.067 & 0.005 & 0.062 \\
\hline & (0.393) & (0.077) & $(0.006)$ & $(0.072)$ & $(0.389)$ & $(0.077)$ & $(0.007)$ & $(0.071)$ \\
\hline \multirow{2}{*}{ s1 } & 0.328 & -0.065 & 0.005 & 0.060 & 0.359 & -0.071 & 0.005 & 0.065 \\
\hline & $(0.388)$ & $(0.076)$ & $(0.006)$ & $(0.071)$ & $(0.384)$ & $(0.075)$ & $(0.007)$ & $(0.070)$ \\
\hline \multirow{2}{*}{$\mathrm{t} 1$} & 0.505 & -0.100 & 0.007 & 0.092 & 0.576 & -0.113 & 0.008 & 0.105 \\
\hline & $(0.481)$ & $(0.094)$ & $(0.008)$ & (0.088) & $(0.476)$ & (0.093) & (0.009) & $(0.086)$ \\
\hline \multirow{2}{*}{$\mathrm{y} 2$} & -0.053 & 0.011 & -0.001 & -0.010 & -0.041 & 0.008 & -0.001 & -0.007 \\
\hline & (0.183) & $(0.036)$ & $(0.003)$ & (0.033) & (0.183) & $(0.036)$ & (0.003) & $(0.033)$ \\
\hline \multirow{2}{*}{ y3 } & -0.102 & 0.020 & -0.001 & -0.019 & -0.089 & 0.017 & -0.001 & -0.016 \\
\hline & $(0.232)$ & $(0.046)$ & $(0.003)$ & $(0.042)$ & $(0.232)$ & $(0.046)$ & $(0.004)$ & $(0.042)$ \\
\hline \multirow{2}{*}{$\mathrm{y} 4$} & -0.239 & 0.047 & -0.003 & -0.044 & -0.202 & 0.040 & -0.003 & -0.037 \\
\hline & $(0.239)$ & $(0.047)$ & $(0.004)$ & $(0.044)$ & $(0.240)$ & $(0.047)$ & $(0.004)$ & $(0.044)$ \\
\hline \multirow{2}{*}{ y5 } & -0.280 & 0.055 & -0.004 & -0.051 & -0.253 & 0.050 & -0.004 & -0.046 \\
\hline & $(0.265)$ & $(0.052)$ & $(0.005)$ & (0.048) & $(0.265)$ & $(0.052)$ & $(0.005)$ & $(0.048)$ \\
\hline toblet & 0.098 & -0.019 & 0.001 & 0.018 & 0.098 & -0.019 & 0.001 & 0.018 \\
\hline tadiet & $(0.075)$ & $(0.015)$ & $(0.001)$ & $(0.014)$ & $(0.075)$ & $(0.015)$ & $(0.001)$ & $(0.014)$ \\
\hline $\mathrm{hn}$ & -0.407 & 0.080 & -0.006 & -0.074 & -0.420 & 0.083 & -0.006 & -0.077 \\
\hline bp & $(0.212)^{\ddagger}$ & $(0.042)^{\ddagger}$ & $(0.005)$ & $(0.039)^{\ddagger}$ & $(0.214)^{*}$ & $(0.042)^{*}$ & $(0.005)$ & $(0.039)^{*}$ \\
\hline tuition & -0.226 & 0.044 & -0.003 & -0.041 & -0.213 & 0.042 & -0.003 & -0.039 \\
\hline tultion & $(0.147)$ & $(0.029)$ & $(0.003)$ & $(0.027)$ & $(0.148)$ & (0.029) & (0.003) & $(0.027)$ \\
\hline ltZenglish & 0.001 & 0.0001 & -0.000 & -0.0001 & -0.012 & 0.002 & -0.0002 & -0.003 \\
\hline Itsengilsn & $(0.210)$ & $(0.041)$ & $(0.003)$ & $(0.038)$ & $(0.213)$ & $(0.042)$ & $(0.003)$ & $(0.039)$ \\
\hline lhmi & 0.193 & -0.038 & 0.001 & 0.035 & 0.481 & -0.095 & 0.007 & 0.088 \\
\hline 10111 & $(0.263)$ & $(0.052)$ & (0.003) & $(0.048)$ & $(0.277)^{\ddagger}$ & $(0.055)^{\ddagger}$ & $(0.006)$ & $(0.050)$ \\
\hline corringe & 0.004 & -0.001 & 0.0001 & 0.001 & 0.004 & -0.001 & 0.0001 & 0.0007 \\
\hline camage & $(0.001)^{*}$ & $(0.0003)^{\ddagger}$ & $(0.0004)$ & $(0.0003)^{*}$ & $(0.001)^{*}$ & $(0.0003)^{*}$ & $(0.00004)$ & $(0.0003)^{*}$ \\
\hline llengths & -0.128 & 0.025 & -0.002 & -0.023 & -0.122 & 0.024 & -0.002 & -0.022 \\
\hline Ilengtns & $(0.329)$ & $(0.065)$ & $(0.005)$ & $(0.060)$ & $(0.326)$ & $(0.064)$ & $(0.005)$ & $(0.060)$ \\
\hline lyoights & 0.235 & -0.047 & 0.003 & 0.043 & - & - & - & - \\
\hline Iweignts & $(0.126)^{\ddagger}$ & $(0.025)^{\ddagger}$ & $(0.003)$ & $(0.023)^{\ddagger}$ & - & - & - & - \\
\hline ехсесs & - & - & - & - & 0.385 & -0.076 & 0.006 & 0.070 \\
\hline excess & - & - & - & - & $(0.157)^{+}$ & $(0.031)^{+}$ & $(0.005)$ & $(0.028)^{+}$ \\
\hline$N$ & & & & & & & & \\
\hline Wald $\chi^{2}(22)$ & & 71.4 & $00]^{*}$ & & & 73.53 & $00]^{*}$ & \\
\hline P Pseudo- $R^{2}$ & & & & & & & & \\
\hline VIF & & & & & & & & \\
\hline Breusch-Pagan & & 2.2 & $35]$ & & & 1.69 & 94] & \\
\hline White & & 286.8 & $421]^{+}$ & & & 306.67 & $005]^{*}$ & \\
\hline Jarque-Bera & & 219.7 & $.000]^{*}$ & & & 215.87 & $000]^{*}$ & \\
\hline Debenedictis-Giles & & 1.74 & 108] & & & 1.525 & 17] & \\
\hline
\end{tabular}

The p-value is given in brackets. ${ }^{*},{ }^{++},{ }^{+}$and denote $1 \%, 5 \%$ and $10 \%$ significance level respectively.

(Author's own calculations)

the duration of bag carriage is associated with small changes in the feeling of SP.

\section{Weights and SP}

Both normal weight and excess weight seem to contribute in the occurrence of SP positively. According to experts, the weight of a school bag must not be more than $10 \%$ of the student's body weight, and weight should be equally distributed on both shoulders (Arghavani et al., 2014). However, in both cases, substantial SP arises which may be due to an uneven distribution of load on the shoulders. Perhaps, the $10 \%$ proposal is challenging (Dockrell et al., 2006) and 
Table 8. Ordered Logit Model for Neck Pains

\begin{tabular}{|c|c|c|c|c|c|c|c|c|}
\hline \multirow{2}{*}{ Variables } & \multicolumn{4}{|c|}{ Model 1} & \multicolumn{4}{|c|}{ Model 2} \\
\hline & Coeff. & ME 1 & ME 2 & ME 3 & Coeff. & ME 1 & ME 2 & ME 3 \\
\hline \multirow{2}{*}{ lage } & 0.043 & -0.010 & 0.003 & 0.007 & 0.088 & -0.020 & 0.007 & 0.013 \\
\hline & $(0.537)$ & $(0.124)$ & $(0.043)$ & $(0.082)$ & $(0.532)$ & $(0.123)$ & $(0.042)$ & $(0.081)$ \\
\hline \multirow{2}{*}{ girls } & 0.465 & -0.107 & 0.037 & 0.071 & 0.489 & -0.113 & 0.039 & 0.074 \\
\hline & $(0.215)^{+}$ & $(0.049)^{+}$ & $(0.017)^{+}$ & $(0.033)^{+}$ & $(0.211)^{+}$ & $(0.048)^{+}$ & $(0.017)^{+}$ & $(0.032)^{+}$ \\
\hline \multirow{2}{*}{ mixed } & 0.871 & -0.201 & 0.069 & 0.132 & 0.915 & -0.211 & -0.004 & 0.139 \\
\hline & $(0.236)^{*}$ & $(0.053)^{*}$ & $(0.019)^{*}$ & $(0.036)^{*}$ & $(0.216)^{*}$ & $(0.048)^{*}$ & $(0.012)^{*}$ & $(0.033)^{*}$ \\
\hline \multirow{2}{*}{ urban } & -0.042 & 0.010 & -0.003 & -0.006 & -0.046 & 0.010 & -0.004 & -0.007 \\
\hline & (0.149) & $(0.034)$ & $(0.012)$ & $(0.023)$ & $(0.151)$ & $(0.035)$ & $(0.012)$ & (0.023) \\
\hline \multirow{2}{*}{$\mathrm{p}$} & -0.669 & 0.152 & -0.052 & -0.100 & -0.634 & 0.146 & -0.051 & -0.096 \\
\hline & $(0.340)^{+}$ & $(0.078)^{+}$ & $(0.027)^{+}$ & $(0.052)^{+}$ & $(0.318)^{+}$ & $(0.073)^{+}$ & $(0.026)^{+}$ & $(0.048)^{+}$ \\
\hline \multirow{2}{*}{$\mathrm{S}$} & -0.588 & 0.140 & -0.047 & -0.089 & -0.557 & 0.129 & -0.044 & -0.085 \\
\hline & $(0.331)^{\ddagger}$ & $(0.076)^{+}$ & $(0.027)^{\ddagger}$ & $(0.050)^{\ddagger}$ & $(0.331)^{\ddagger}$ & $(0.072)^{\ddagger}$ & $(0.025)^{\ddagger}$ & $(0.047)^{\ddagger}$ \\
\hline \multirow[b]{2}{*}{$\mathrm{t}$} & -0.669 & 0.155 & -0.053 & -0.102 & -0.649 & 0.150 & -0.051 & -0.099 \\
\hline & $(0.402)^{\ddagger}$ & $(0.092)^{\ddagger}$ & $(0.032)^{\ddagger}$ & $(0.061)^{\ddagger}$ & $(0.375)^{\ddagger}$ & $(0.086)^{\ddagger}$ & $(0.030)^{\ddagger}$ & $(0.057)^{\ddagger}$ \\
\hline \multirow{2}{*}{$\mathrm{p} 1$} & 0.190 & -0.044 & 0.015 & 0.030 & 0.209 & -0.048 & 0.017 & 0.032 \\
\hline & $(0.418)$ & (0.097) & $(0.033)$ & $(0.063)$ & (0.359) & (0.083) & $(0.029)$ & $(0.054)$ \\
\hline \multirow{2}{*}{$\mathrm{s} 1$} & 0.260 & -0.060 & 0.021 & 0.039 & 0.275 & -0.064 & 0.022 & 0.042 \\
\hline & $(0.404)$ & (0.093) & $(0.032)$ & $(0.061)$ & (0.347) & $(0.080$ & $(0.028)$ & $(0.053)$ \\
\hline \multirow{2}{*}{$\mathrm{t} 1$} & 0.814 & -0.189 & 0.064 & 0.124 & 0.848 & -0.196 & 0.067 & 0.130 \\
\hline & $(0.489)^{\ddagger}$ & $(0.112)^{\ddagger}$ & $(0.040)$ & $(0.074)^{+}$ & $(0.429)^{+}$ & $(0.098)^{+}$ & $(0.035)^{+}$ & $(0.065)^{+}$ \\
\hline \multirow{2}{*}{$\mathrm{y} 2$} & 0.231 & -0.053 & 0.018 & 0.035 & 0.238 & -0.055 & 0.019 & 0.036 \\
\hline & $(0.190)$ & $(0.044)$ & $(0.015)$ & $(0.029)$ & $(0.183)$ & $(0.042)$ & $(0.015)$ & $(0.028)$ \\
\hline \multirow{2}{*}{ y3 } & 0.265 & -0.061 & 0.021 & 0.040 & 0.273 & -0.063 & 0.022 & 0.041 \\
\hline & $(0.232)$ & $(0.053)$ & (0.019) & $(0.035)$ & $(0.222)$ & $(0.051)$ & $(0.018)$ & $(0.034)$ \\
\hline \multirow{2}{*}{$\mathrm{y} 4$} & -0.005 & 0.001 & -0.0004 & -0.0008 & 0.014 & -0.003 & 0.001 & 0.002 \\
\hline & $(0.244)$ & $(0.056)$ & $(0.019)$ & $(0.037)$ & $(0.234)$ & $(0.054)$ & (0.019) & $(0.035)$ \\
\hline \multirow{2}{*}{ y5 } & 0.113 & -0.026 & 0.010 & 0.017 & 0.129 & -0.030 & 0.011 & 0.020 \\
\hline & $(0.275)$ & $(0.063)$ & $(0.022)$ & $(0.042)$ & $(0.258)$ & $(0.060)$ & $(0.021)$ & (0.039) \\
\hline & 0.133 & -0.031 & 0.011 & 0.020 & 0.134 & -0.031 & 0.011 & 0.020 \\
\hline tablet & $(0.071)^{\ddagger}$ & $(0.016)^{\ddagger}$ & $(0.006)^{\ddagger}$ & $(0.011)^{\ddagger}$ & $(0.072)^{\ddagger}$ & $(0.016)^{\ddagger}$ & $(0.006)^{\ddagger}$ & $(0.011)^{\ddagger}$ \\
\hline $\mathrm{hn}$ & -0.113 & 0.026 & -0.009 & -0.017 & -0.116 & 0.027 & -0.009 & -0.018 \\
\hline $\mathrm{bp}$ & $(0.198)$ & $(0.046)$ & $(0.016)$ & $(0.030)$ & $(0.192)$ & $(0.044)$ & $(0.015)$ & (0.029) \\
\hline tuition & 0.035 & -0.008 & 0.003 & 0.005 & 0.038 & -0.008 & 0.003 & 0.006 \\
\hline turtion & $(0.150)$ & $(0.034)$ & $(0.012)$ & $(0.023)$ & $(0.140)$ & $(0.032$ & $(0.011)$ & $(0.021)$ \\
\hline lt3english & 0.425 & -0.098 & 0.034 & 0.065 & 0.424 & -0.098 & 0.034 & 0.064 \\
\hline Itsengilsn & $(0.201)^{+}$ & $(0.048)^{+}$ & $(0.017)^{\ddagger}$ & $(0.032)^{+}$ & $(0.192)^{+}$ & $(0.044)^{\ddagger}$ & $(0.016)^{+}$ & $(0.029)^{+}$ \\
\hline & 0.218 & -0.050 & 0.017 & 0.033 & 0.373 & -0.086 & 0.012 & 0.057 \\
\hline lbmi & $(0.266)$ & $(0.061)$ & $(0.021)$ & $(0.040)$ & $(0.294)$ & $(0.068)$ & $(0.021)$ & $(0.045)$ \\
\hline carriage & 0.003 & -0.001 & 0.002 & 0.000 & 0.003 & -0.001 & 0.002 & 0.0004 \\
\hline carriage & $(0.001)^{+}$ & $(0.0003)^{+}$ & $(0.000)^{+}$ & $(0.0002)^{+}$ & $(0.001)^{+}$ & $(0.0003)^{+}$ & $(0.000)^{\ddagger}$ & $(0.0002)^{+}$ \\
\hline llengths & 0.069 & -0.016 & 0.005 & 0.010 & 0.073 & -0.017 & 0.006 & 0.011 \\
\hline llengtns & $(0.327)$ & $(0.076)$ & $(0.026)$ & $(0.050)$ & $(0.280)$ & $(0.065)$ & $(0.022)$ & $(0.042)$ \\
\hline lweights & 0.162 & -0.037 & 0.013 & 0.025 & - & - & - & - \\
\hline Iweignts & $(0.127)$ & $(0.029)$ & $(0.010)$ & $(0.020)$ & - & - & - & - \\
\hline & - & - & - & - & 0.204 & -0.047 & 0.016 & 0.031 \\
\hline excess & - & - & - & - & $(0.161)$ & $(0.037)$ & $(0.013)$ & $(0.031)$ \\
\hline$N$ & & & & & & & & \\
\hline Wald $\chi^{2}(22)$ & & 41 & $.008]^{*}$ & & & 42.67 & $05]^{*}$ & \\
\hline P Pseudo- $R^{2}$ & & & & & & & & \\
\hline VIF & & & & & & & & \\
\hline Breusch-Pagan & & & $.739]$ & & & 0.07 & 98] & \\
\hline White & & 24 & [0.452] & & & 247.3 & 483] & \\
\hline Jarque-Bera & & 182 & $0.000]^{*}$ & & & 182.7 & $000]^{*}$ & \\
\hline Debenedictis-Giles & & & $0.930]$ & & & 0.30 & 581] & \\
\hline
\end{tabular}

The p-value is given in brackets. ${ }^{*},{ }^{++},{ }^{+}$and denote $1 \%, 5 \%$ and $10 \%$ significance level respectively.

(Source: Author's own calculations)

education stakeholders will have to consider the $5 \%$ student's body weight (Rai \& Agarawal, 2013). The marginal effects in Model 1 suggest that an increase in the use of backpack by students in schools is associated with around $5 \%$ less likely not to experience SP and about $4 \%$ more likely to always get SP. In Model 2 an increase in the use of backpack by students in schools is associated with around 8\% less likely not to experience SP and about 7\%more likely to always get SP.

\section{Models for NP}

The logistic regression (Model 5) in Table 8 discloses that gender, father's education level, the perception of replacing 
books with Tablets, English language performance and the duration of bag carriage bag are explanatory variables of NP. The $\mathrm{R}^{2}$ for both Models is found to be 0.024 . It confirms that both Models are relatively satisfying since it is between 0 and 1. For R2 to rise, there should be an increase in sample size. The Jarque-Bera test is highly significant confirming normality of the data.

\section{Gender and NP}

Regarding gender, girls more than boys have positive significant $(p<0.05)$ effect of experiencing NP. Similarly, other studies indicate that the occurrence of NP complaints is more common in females than males (Dianat et al., 2014; Mikklesson et al., 1997). From Table 8, the marginal effects in Model 1 suggest that an increase in the number of girl's students in schools is associated with around 11\% less likely to not experience NP and 4\% more likely to sometimes get pain and $7 \%$ more likely to always get pain. The marginal effects in Model 2 suggest that an increase in the number of girl's students in schools is associated with around $1 \%$ less likely to not experience NP and $4 \%$ more likely to sometimes get pain and $8 \%$ more likely to always, get pain.

For students in mixed schools, the positive coefficient is higher in both models and the marginal effects. Model 1 suggest that an increase in the number of girl's students 'in schools is associated with around $20 \%$ less likely to not experience NP and 7\% more likely to sometimes get pain and $13 \%$ more likely to always get pain but model 2suggest that an increase in the number of girl's students 'in schools is associated with around $21 \%$ less likely to not experience NP and $4 \%$ less likely to sometimes get pain and $14 \%$ more likely to always get pain. It shows that there is a difference between normal weight and excess weight as regard to mixed students. According to a recent inquiry neck and SP are linked to gender, mainly women (Hanvold et al., 2014; Yeun, 2017).

\section{Parental education level and NP}

An increase in father's education levels has a negative significant impact on NP ( $p<0.05$ and $p<0.1)$ occurrence. Students having the intention to replace books with tablets suffer from significant $(\mathrm{p}<0.1) \mathrm{NP}$ as report models 1 and 2 . However, this is in contrast to other studies indicating that many physical discomforts are associated with tablet use including MSP in many regions of the body (Calisir \& Akdag, 2017; Kim et al., 2014; Lee et al., 2018; Uyal et al., 2017).

\section{Tablet and NP}

Regarding the perception about replacing some books with tablets, there is a significant impact $(\mathrm{p}<0.1)$ to experience NP. Thus, students having NP are more likely to go with this change. Such behaviour is linked to the results of some studies suggesting that heavily loaded backpacks laden with textbooks can cause various back and health problems (Embong et al., 2012; Van Heerden \& Van Belle, 2013). From Table 8, the marginal effects in models 1 and 2 suggest that an increase in such perception has a minor significant impact on the different levels of NP.

\section{Performance and NP}

This work shows that English performance is positively connected to NP $(p<0.05)$ in both models in support of another research where the high performance of students is linked with lower BP, and lower neck and SP as the students are less stressed (Shan et al., 2013). However, a different result indicates that a decrease in student's concentration and academic performance are associated with NP (Ayanniyi et al., 2010). The marginal effects in Model 1 suggest that an increase in performance is associated with around $10 \%$ less likely to not experience NP and 3\% more likely to sometimes get pain and $6 \%$ more likely to always get pain. But Model 2 suggest that an increase in performance is associated with around 3\% less likely to not experience NP and 3\% less likely to sometimes get pain and 6\% more likely to always get pain.

\section{Duration of bag carriage and NP}

The duration of bag carriage is slightly associated with NP in this study ( $p<0.05)$. Balamurugan, (2014) finds a positive between longer lengths of time students carry their bags and NP. But to date, very few studies have investigated whether the duration of school bag carriage is related with adolescent NP (Haselgrove et al., 2008). Khalid et al. (2018) find that the DBC of schoolbags has no association with neck pain $(p>0.05)$.

\section{Discussions}

The research question in this investigation is:

\section{What are the factors causing MSP among students?}

The five different models helped to extract valuable research findings regarding the effects of some respective factors on the occurrence of body pains. The demographic factor age does not show any association between neck, shoulder and lower back (NSLB) complaints in line with the results of one study (Dianat et al., 2013). However, other studies have shown an increase in NSLB pains with age (Panicker \& Sandesh, 2014; Sato et al., 2008; Siivola et al., 2004).

The results for gender and its association with pain confirm literature whereby females are more likely to experience pains compared to males (Bailey, 2009; Fillingim, 2003; Leveille et al., 2001; Wáng et al., 2016). For example, DP and LBP is more likely in girls of age 14 than boys of the same cohort (Kedra \& Czaprowski, 2013; Korovessis, 2004). Female students too are more susceptible to BP (Kellis \& Emmanouilidou, 2010) and a plausible explanation for males experiencing less LBP is their physical fitness with stronger muscles (Harreby et al., 1997; Triki et al., 2015). Students in mixed schools also experience MSP related pains which may be related to the female composition as it is suggested that females diagnose and state their symptoms more sensitively than males (Siivola, 2003).

Similarly, the occurrence of SP and NP and low back complaints are more common in females than males (Dianat et al., 2014; Mikklesson et al., 1997; Siivola, 2003). According to a recent inquiry neck and SP are linked to gender, mainly women (Yeun, 2017). However, another recent investigation indicates no significant difference between males and females (Malik et al., 2017; Melo-Marins et al., 2015). Under the NYCBE curriculum, the introduction of non-core subjects (Table 2) like oral expression may help the pain reporting differences 
between boys and girls (Rajan \& Koti, 2013). The disparity in physical fitness between boys and girls may fade by emphasizing the implementation of practical physical education and health programs mainly in girl's school.

This study displays no significant association between location and MSP in agreement with some previous studies on students (AL-Qato et al., 2012; El-Nagar \& Mady, 2017; Lewandowski \& Lukaszewska, 2014). Under the NYCBE, maintaining the provision of free transport services alongside with the zoning systems may be helping students to avoid MSP.

Socio-economic deficiencies are related to poor health among students (Power, 1991). For the question of parental literacy level, the results indicate mother's education levels have greater impacts on pains in general compared to father's education levels consistent with a recent finding (El-Nagar \& Mady, 2017). In a review, parental education significantly impacts chronic pains (King et al., 2011; Kumar et al., 2017). One study indicates that family income level impacts on BP which is in line with a recent report (Smith et al., 2017). However, an inquiry shows no significant association between family income and pains (Diepenmaat et al., 2006) and another research states that socio-economic status alone is not reliably linked to LBP, but clusters of other problems may favour LBP (Mikkonen, 2015).

This study significantly indicates that students that who feel BPs prefer to switch to a tablet. Such a perception matches with literature whereby carrying e-Textbooks on a light appliance is better than being loaded with the extra weight of traditional paper books (Zimerman, 2011). College researches demonstrate that deeply overloaded backpacks containing textbooks can lead diverse back and health troubles (Embong, et al., 2012; Van Heerden \& Van Belle, 2013). However, it seems that students are willing to experience this innovation, and they are naive with respect to many physical discomforts associated with tablet use including MSP in many regions of the body (Calisir \& Akdag, 2017; Kim et al. 2014; Lee et al., 2018; Uyal et al., 2017). Carrying backpack relative to shoulder bag and handbag is associated with NP and SP asserting other investigations (Dianat et al., 2014; Freedman, 2009) and this may be due to the way and mode in which the backpack is carried (Candotti et al., 2012; Fernandes et al., 2008; MeloMarins, 2015). Asymmetric load distribution is also responsible for MSP in students (Yoon, 2014). Carrying a backpack on both shoulders is the optimum and safer method. The NYCBE needs to highlight the stipulation of lockers and functional libraries in all schools in order to avoid excessive loading and recurring strain injuries.

The models reveal shows that the academic performance of students is associated with overall body pains as indicates additional research (Sampaio et al., 2016). A possible explanation for such pains is academic pressure and psychological pressure in relation due to the approaching exams and the reduction of physical activity caused by the academic burden (Shan et al., 2013). It may also be due to subjects like sports, and physical education involving effort, spinal mobility and flexibility of muscles and joints as they are associated with LBP (Fairbank et al., 1984; Mierau et al., 1989; Triki et al., 2015). A similar association occurs between the prevalence of a chronic headache and BP and excellent academic success (Gobina, 2011). However, a different result indicates that a decrease in student's concentration and academic performance are associated with NP (Ayanniyi et al., 2010). Still another research suggests that high performance of students is linked with lower BP and lower neck and SP as the students are less stressed (Shan et al., 2013). Under the new curriculum, students need to get more exposures to physical education, the arts including dance and theatre to relieve stress but it is important to prescribe the correct dozes to prevent LBP. The training and education of educators by expert physicians regarding MSP is crucial for the smooth transition of students towards the completion of education. Workshops and seminars on musculoskeletal education involving students, parents and educators require due attention in the NYCBE program.

Tuition is not associated with MSP in Mauritius in contradiction with the notion of heavy tuition books and hard work displayed by these two studies (George et al., 2015; McGrady \& Moss, 2018). No association is seen between BMI and pains and similar results are reported by some studies (Dianat et al., 2014; Kwon, 2006; Tantawy et al., 2017). The duration of bag carriage is directly associated with pains in various regions of the body and reveals to be a significant explanatory variable. A longer period of carrying a school bag may increase the risk of adolescent BP (Aundhakar et al., 2015; Grimmer \& Williams 2000; Paušić et al., 2013). It is likely that the risk factors for MSP are connected with the duration of schoolbag carriage combined with effects of heavy loads, load shape, size and location of the load on the body (Chansirinukor et al., 2001). But to date, very few studies have investigated whether the duration of school bag carriage is related with adolescent NP (Haselgrove et al., 2008).

In this study, the length of straps does not associate with pains measured similar to research by Yoon (2014). Similarly, another study shows that the straps length does have an effect on upper trapezius pain threshold in shoulders (Abdelraouf et al., 2016). There is a lack of literature on the proper length and level of backpack shoulder straps. Still, some studies are in favour of two straps bags relative to one strap as it is believed to be ergonomic (Grimmer et al., 1999; Springett \& Wise, 2007). According to experts, the weight of a school bag must not be more than $10 \%$ of the student's body weight, and weight should be equally distributed on both shoulders (Arghavani et al., 2014).

However, in this study overall pains are observed even below $10 \%$ of body weight and the intensity of pains increases linearly with excess \% body weight as illustrated in many independent types of research (Brackley \& Stevenson 2004; Hong \& Cheung, 2003; Pascoe et al., 1997; Paušić et al., 2013; Walicka-Cupry et al., 2015). In both cases, strong shoulder BP arises which may be due to an uneven distribution of load on the shoulders. Perhaps, education stakeholders will have to consider the 5\% student's body weight (Rai \& Agarawal, 2013).

In general, our students are prone to MSP. Under the NYCBE human capital objectives, it is important to consider the following research findings for proper realization of the proposed education changes by 2030 . Firstly, musculoskeletal education by expert physicians is highly recommended to all students and educators so that there is cohesion between physical education, student health and academic performance. 
The provision of lockers, the use of lighter term-wise based books are preventive vaccines against the problem of excessive bag weights and associated MSP discomforts. Finally, for a minimum stressed mind setting due to MSP and an optimum academic performance the help of art forms under non-core subjects is greatly suggested.

\section{CONCLUSION AND RECOMMENDATIONS}

The study focuses on objectives 4-6 (Table 1) signifying the importance of the human capital perspective in education. Literature reveals that MSP is proving to be one of the main non-communicable diseases gaining field among students and weakened musculoskeletal health is accountable for the loss of productive life years in the labour force. The investigation of the prevalence and factors associated with MSP in Tables 4-8 indicate that students from single-sexed girl and mixed schools relative to boys' schools, student perception of tablet use, backpack schoolbag relative to handbag and shoulderbag, performance, duration of bag carriage, total weight and excess weight of schoolbags have significant positive impact on musculoskeletal pain. The summary statistics in Table 3 of the research informs about the occurrence of MSP among $89 \%$ Mauritian students. The NYCBE is under threat and corrective measures impose.

Health can impact academic performance, and therefore it should be the concern of the legal system to guarantee it to its population. Under the curriculum, the use of tablets to replace some books may contribute to decreasing the bag weights, and the use of term wise books as it is the case in grades 1 to 6 should be extended to higher grades. The availability of lockers at schools may bring relief to students from both normal weight and excess weight of bags and associated MSP. Consistent and stable lives are crucial for healthy psychological development. Family disrupts and court decisions to change geographical regions should be the last resort (Gindes, 1998). For instance, children engaging in hard physical activities should be medically screened first and then channeled to specific tracks instead of being selected on endurance and performance criteria. Grants could also be provided to empower parents to assist their children in eating a healthy diet (Wang et al., 2011). Long waiting time on bus stops with heavy bags should be avoided by proper management of the free transport services.

Future work on the prevalence and factors associated with MSP among secondary school students can be reproduce with larger sample sizes in by including other secondary schools. It is worthy to use lower grades students from primary schools and tertiary level students to have a better comprehension of the correlation between ages, bag weight, DBC, performance and MSP. For instance, the study does cater for measurements in pain intensity which is crucial in policy implication. So, future work can identify ways to evaluate the impact of pain using multidimensional pain scales.

Author contributions: All co-authors have involved in all stages of this study while preparing the final version. They all agree with the results and conclusions.

Funding: No external funding is received for this article.
Declaration of interest: The authors declare that they have no competing interests.

Ethics approval and consent to participate: Not applicable. Availability of data and materials: All data generated or analyzed during this study are available for sharing when appropriate request is directed to corresponding author.

\section{REFERENCES}

Abdelraouf, O. R., Hamada, H. A., Selim, A., Shendy, W., \& Zakaria, H. (2016). Effect of backpack shoulder straps length on cervical posture and upper trapezius pressure pain threshold. Journal of Physical Therapy Science, 28(9), 2437-2440. https://doi.org/10.1589/jpts.28.2437

Al-Hazzaa, H. M. (2006). School backpack. How much load do Saudi school boys carry on their shoulders?. Saudi Medical Journal, 27(10), 1567-1571.

Al-Qato, A.O., Issa, K., \& Abu-Hijleh, G. (2012). The Influence of Backpacks on Students backs: A Cross-Sectional Study of Schools in Tulkarm District (Doctoral dissertation, Masters Thesis. An-Najah National University).

Alshagga, M. A., Nimer, A. R., Yan, L. P., Ibrahim, I. A. A., AlGhamdi, S. S., \& Al-Dubai, S. A. R. (2013). Prevalence and factors associated with neck, shoulder and low back pains among medical students in a Malaysian Medical College. BMC Research Notes, 6(1), 244. https://doi.org/10.1186/ 1756-0500-6-244

Annand, D. (2008). Learning efficacy and cost-effectiveness of print versus e-book instructional material in an introductory financial accounting course. Journal of Interactive Online Learning, 7(2), 152-164.

Arghavani, F., Alizadeh, H., Rahmani, K., Rezai, L., Bidarpoor, F., \& Bigi, F. (2016). Prevalence and causes of musculoskeletal pain among middle school students in Sanandaj, Iran. https://doi.org/10.18869/acadpub.jrh.6.5. 465

Arghavani, F., Zamanian, Z., Ghanbary, A., \& Hassanzadeh, J. (2014). Investigation of the relationship between carrying school bags (handbags and backpacks) and the prevalence of musculoskeletal pains among 12-15-year-old students in Shiraz. Pakistan Journal of Biological Sciences, 17(4), 550554. https://doi.org/10.3923/pjbs.2014.550.554

Aundhakar, C. D., Bahatkar, K. U., Padiyar, M. S., Jeswani, D. H., \& Colaco, S. (2015). Back pain in children associated with backpacks. Indian Journal of Pain, 29(1), 29. https://doi.org/10.4103/0970-5333.145941

Ayanniyi, O., Mbada, C. E., \& Iroko, O. P. (2010). NP occurrence and characteristics in Nigerian University undergraduates. TAF Preventive Medicine Bulletin, 9(3).

Bailey, A. L., \& Butler, F. A. (2003). An evidentiary framework for operationalizing academic language for broad application to K-12 education: A design document. Center for the Study of Evaluation, National Center for Research on Evaluation, Standards, and Student Testing, Graduate School of Education \& Information Studies, University of California, Los Angeles. 
Balague, F., Dutoit, G., \& Waldburger, M. (1998), Low BP in schoolchildren. Scandinavian Journal of Rehabilitative Medicine, 20, 175-179.

Balamurugan, J. (2014). School bags and musculoskeletal pain among elementary school children in Chennai city. International Journal of Medical Science and Clinical Invention, 1, 302-309.

Brackley, H. M., \& Stevenson, J. M. (2004). Are children's backpack weight limits enough?: A critical review of the relevant literature. Spine, 29(19), 2184-2190. https://doi.org/10.1097/01.brs.0000141183.20124.a9

Breusch, T. S., \& Pagan, A. R. (1979). Simple test for heteroscedasticity and random coefficient variation. Econometrica, 47, 1287-1294. https://doi.org/10.2307/ 1911963

Briggs, A. M., Woolf, A. D., Dreinhöfer, K., Homb, N., Hoy, D. G., Kopansky-Giles, D., Åkesson, K., \& March, L. (2018). Reducing the global burden of musculoskeletal conditions. Bulletin of the World Health Organization, 96(5), 366. https://doi.org/10.2471/BLT.17.204891

Brzęk, A., Dworrak, T., Strauss, M., Sanchis-Gomar, F., Sabbah, I., Dworrak, B., \& Leischik, R. (2017). The weight of pupils' schoolbags in early school age and its influence on body posture. BMC Musculoskeletal Disorders, 18(1), 1-11. https://doi.org/10.1186/s12891-017-1462-z

Bullard, H. C. (2011). The effects of school enrollment size on student achievement.

Burgess, S. M. (2016). Human capital and education: The state of the art in the economics of education.

Burke, A. M. (1987). Making a big school smaller: The schoolwithin-a-school arrangement for middle level schools.

Burton, K. D., Lydon, J. E., D’alessandro, D. U., \& Koestner, R. (2006). The differential effects of intrinsic and identified motivation on well-being and performance: prospective, experimental, and implicit approaches to selfdetermination theory. Journal of Personality and Social Psychology, 91(4), 750. https://doi.org/10.1037/00223514.91.4.750

Calisir, F., \& Akdag, H. C. (Eds.) (2017). Industrial engineering in the industry 4.0 era. Selected papers from the global joint conference on industrial engineering and its application areas, GJCIE 2017, July 20-21, Vienna, Austria. Springer.

Callahan, L. F., Rao, J., \& Boutaugh, M. (1996). Arthritis and women's health: Prevalence, impact, and prevention. American Journal of Preventive Medicine, 12(5), 401-409. https://doi.org/10.1016/S0749-3797(18)30298-8

Candotti, C. T., Noll, M., \& Roth, E. (2012). Avaliação do peso e do modo de transporte do material escolar emalunos do ensino fundamental [Evaluation of the weight and mode of transport of school supplies in elementary school students]. Revista Paulista De Pediatria, 30(1), 100-106. https://doi.org/10.1590/S0103-05822012000100015

Chansirinukor, W., Wilson, D., Grimmer, K., \& Dansie, B. (2001). Effects of backpacks on students: Measurement of cervical and shoulder posture. Australian Journal of Physiotherapy, 47(2), 110-116. https://doi.org/10.1016/ S0004-9514(14)60302-0
Chen, Y. L., \& Mu, Y. C. (2018). Effects of backpack load and position on body strains in male schoolchildren while walking. PloS one, 13(3), e0193648. https://doi.org/ 10.1371/journal.pone.0193648

Darmawan, J., Valkenburg, H. A., Muirden, K. D., \& Wigley, R. D. (1992). Epidemiology of rheumatic diseases in rural and urban populations in Indonesia: A World Health Organisation international league against rheumatism COPCORD study, Stage I, Phase 2. Annals of the Rheumatic Diseases, 51(4), 525. https://doi.org/10.1136/ard.51.4.525

David, A. C. (2007). HIV/AIDS and social capital in a crosssection of countries. The World Bank. https://doi.org/10.1596/1813-9450-4263

DeBenedictis, L. F., \& Giles, D. E. A. (1998). Diagnostic testing in econometrics: Variable addition, RESET and fourier approximations. In A. Ullah, \& D. E. A. Giles (Eds.). Handbook of applied economic statistics (pp. 383-417). Marcel Dekker.

Deeney, C., \& O’Sullivan, L. (2009). Work related psychosocial risks and musculoskeletal disorders: Potential risk factors, causation and evaluation methods. Work, 34(2), 239-248. https://doi.org/10.3233/WOR-2009-0921

Dianat, I., Javadivala, Z., Asghari-Jafarabadi, M., Asl Hashemi, A., \& Haslegrave, C. M. (2013). The use of schoolbags and musculoskeletal symptoms among primary school children: Are the recommended weight limits adequate?. Ergonomics, 56(1), 79-89. https://doi.org/10.1080/ 00140139.2012.729612

Dianat, I., Sorkhi, N., Pourhossein, A., Alipour, A., \& AsghariJafarabadi, M. (2014). Neck, shoulder and low BP in secondary schoolchildren in relation to schoolbag carriage: Should the recommended weight limits be gender-specific? Applied Ergonomics, 45(3), 437-442. https://doi.org/ 10.1016/j.apergo.2013.06.003

Diepenmaat, A. C. M., Van Der Wal, M. F., De Vet, H. C. W., \& Hirasing, R. A. (2006). Neck/shoulder, low back, and arm pain in relation to computer use, physical activity, stress, and depression among Dutch adolescents. Pediatrics, 117(2), 412-416. https://doi.org/10.1542/peds.2004-2766

Dockrell, S., Kane, C., \& O’keefe, E. (2006). Schoolbag weight and the effects of schoolbag carriage on secondary school students. Ergonomics, 9, 216-222.

Dockrell, S., Simms, C., \& Blake, C. (2015). Schoolbag carriage and schoolbag-related musculoskeletal discomfort among primary school children. Applied Ergonomics, 51, 281-290. https://doi.org/10.1016/j.apergo.2015.05.009

Drzał-Grabiec, J., Snela, S., Rachwał, M., Rykała, J., \& Podgórska, J. (2013). Effects of carrying a backpack in a symmetrical manner on the shape of the feet. Ergonomics, 56(10), 1577-1583. https://doi.org/10.1080/00140139. 2013.828102

El-Nagar, S. A., \& Mady, M. M. (2017). School bag usage, postural and behavioral habits and its effect on back pain occurrence among school children.

Embong, A. M., Noor, A. M., Hashim, H. M., Ali, R. M., \& Shaari, Z. H. (2012). E-books as textbooks in the classroom. Procedia-Social and Behavioral Sciences, 47, 1802-1809. https://doi.org/10.1016/j.sbspro.2012.06.903 
Fairbank, J. C., Pynsent, P. B., Van, J. P., \& Phillips, H. (1984). Influence of anthropometric factors and joint laxity in the incidence of adolescent BP. Spine, 9(5), 461-464. https://doi.org/10.1097/00007632-198407000-00007

Feldt, R., Angelis, L., Torkar, R., \& Samuelsson, M. (2010). Links between the personalities, views and attitudes of software engineers. Information and Software Technology, 52(6), 611-624. https://doi.org/10.1016/j.infsof.2010.01. 001

Fernandes, S. M. D. S., Casarotto, R. A., \& João, S. M. A. (2008). Efeitos de sessões educativas no uso das mochilas escolares em estudantes do ensino fundamental [Effects of educational sessions on the use of school bags on elementary school students]. Revista Brasileira De Fisioterapia, 12(6), 447-453. https://doi.org/10.1590/ S1413-35552008005000002

Fillingim, R. B. (2003). Sex, gender and pain: The biopsychosocial model in action $\mathrm{XX}$ vs. $\mathrm{XY}$. The International Journal of Sex Differences in the Study of Health, Disease and Aging, 1, 98-101.

Fomby, T. B., Johnson, S. R., \& Hill, R. C. (1984). Review of ordinary least squares and generalized least squares. In Advanced econometric methods (pp. 7-25). Springer. https://doi.org/10.1007/978-1-4419-8746-4_2

Freedman, T. Z. (2009). A kindle in every backpack: A proposal for etextbooks in American schools.

Frisch, R. (1970). From utopian theory to practical applications: The case of econometrics. In Economic Planning Studies (pp. 1-39). Springer. https://doi.org/10.1007/978-94-010-1895-1_1

George, D., Nayak, B. S., \& Shetty, S. (2015). Bag pack weight and musculoskeletal discomfort among school children. Nursing and Midwifery Research, 11(3), 97. https://doi.org/10.33698/NRF0188

Gindes, M. (1998). The psychological effects of relocation for children of divorce. Journal of American Academy of Matrimonial Lawyers, 15, 119.

Goldin, C., \& Katz, L.F., 1999. Human capital and social capital: the rise of secondary schooling in America, 19101940. Journal of interdisciplinary history, 29(4), 683-723. https://doi.org/10.1162/002219599551868

Goodgold, S., Corcoran, M., Gamache, D., Gillis, J., Guerin, J., \& Coyle, J. Q. (2002). Backpack use in children. Pediatric Physical Therapy: The Official Publication of the Section on Pediatrics of the American Physical Therapy Association, 14(3), 122-131. https://doi.org/10.1097/01.PEP.0000028 834.19877.54

Greene, W. H. (2000). Econometric analysis (International edition).

Grimmer, K. A., Williams, M. T., \& Gill, T. K. (1999). The associations between adolescent head-on-neck posture, backpack weight, and anthropometric features. Spine, 24(21), 2262. https://doi.org/10.1097/00007632199911010-00015
Grimmer, K., \& Williams, M. (2000). Gender-age environmental associates of adolescent low BP. Applied Ergonomics, 31, 343-360. https://doi.org/10.1016/S00036870(00)00002-8

Hakala, P. T., Saarni, L. A., Punamäki, R. L., Wallenius, M. A., Nygård, C. H., \& Rimpelä, A. H. (2012). Musculoskeletal symptoms and computer use among Finnish adolescentspain intensity and inconvenience to everyday life: A crosssectional study. BMC Musculoskeletal Disorders, 13(1), 41. https://doi.org/10.1186/1471-2474-13-41

Hakala, P., Rimpelä, A., Salminen, J. J., Virtanen, S. M., \& Rimpelä, M. (2002). Back, neck, and pain in Finnish adolescents: national cross sectional surveys. BMJ, 325(7367), 743. https://doi.org/10.1136/bmj.325.7367.743

Hanvold, T. N., Wærsted, M., Mengshoel, A. M., Bjertness, E., Twisk, J., \& Veiersted, K. B. (2014). A longitudinal study on risk factors for neck and SP among young adults in the transition from technical school to working life. Scandinavian Journal of Work, Environment \& Health, 597609. https://doi.org/10.5271/sjweh.3437

Haq, S. A., Darmawan, J., Islam, M. N., Uddin, M. Z., Das, B. B., Rahman, F., Chowdhury, M. A. J., Alam, M. N., Mahmud, T. A. K., Chowdhury, M. R., \& Tahir, M. (2005). Prevalence of rheumatic diseases and associated outcomes in rural and urban communities in Bangladesh: A COPCORD study. The Journal of Rheumatology, 32(2), 348-353.

Haselgrove, C., Straker, L., Smith, A., O’sullivan, P., Perry, M., \& Sloan, N. (2008). Perceived school bag load, duration of carriage, and method of transport to school are associated with spinal pain in adolescents: An observational study. Australian Journal of Physiotherapy, 54(3), 193-200. https://doi.org/10.1016/S0004-9514(08)70026-6

Hashemi, M., Azizinezhad, M., Najafi, V., \& Nesari, A. J. (2011). What is mobile learning? Challenges and capabilities. Procedia-Social and Behavioral Sciences, 30, 2477-2481. https://doi.org/10.1016/j.sbspro.2011.10.483

Hendi, O. M., Abdulaziz, A. A., Althaqafi, A. M., Hindi, A. M., Khan, S. A., \& Atalla, A. A. (2019). Prevalence of musculoskeletal disorders and its correlation to physical activity among health specialty students. International Journal of Preventive Medicine, 10. https://doi.org/10.4103/ijpvm.IJPVM_436_18

Hershkovich, O., Friedlander, A., Gordon, B., Arzi, H., Derazne, E., Tzur, D., Shamis, A., \& Afek, A. (2013). Associations of body mass index and body height with low BP in 829,791 adolescents. American Journal of Epidemiology, 178(4), 603609. https://doi.org/10.1093/aje/kwt019

Hestbaek, L., Korsholm, L., Leboeuf-Yde, C., \& Kyvik, K. O. (2008). Does socioeconomic status in adolescence predict low BP in adulthood? A repeated cross-sectional study of 4,771 Danish adolescents. European Spine Journal, 17(12), 1727. https://doi.org/10.1007/s00586-008-0796-5 
Hogg-Johnson, S., Van Der Velde, G., Carroll, L. J., Holm, L. W., Cassidy, J. D., Guzman, J., Côté, P., Haldeman, S., Ammendolia, C., Carragee, E., \& Hurwitz, E. (2009). The burden and determinants of NP in the general population: Results of the bone and joint decade 2000-2010 task force on NP and its associated disorders. Journal of Manipulative and Physiological Therapeutics, 32(2), S46-S60. https://doi.org/10.1016/j.jmpt.2008.11.010

Holman, 1966. Medical Research Council's Committee on the aetiology of chronic bronchitis. Instructions for the Use of the Questionnaire on Respiratory Symptoms: Devon, Australia.

Hong, Y., \& Cheung, C. K. (2003). Gait and posture responses to backpack load during level walking in children. Gait and Posture, 17(1), 28-33. https://doi.org/10.1016/S09666362(02)00050-4

Hong, Y., Li, J. X., \& Fong, D. T. P. (2008). Effect of prolonged walking with backpack loads on trunk muscle activity and fatigue in children. Journal of Electromyography and Kinesiology, 18(6), 990-996. https://doi.org/10.1016/ j.jelekin.2007.06.013

Hoy, D., Geere, J. A., Davatchi, F., Meggitt, B., \& Barrero, L. H. (2014). A time for action: Opportunities for preventing the growing burden and disability from musculoskeletal conditions in low-and middle-income countries. Best Practice \& Research Clinical Rheumatology, 28(3), 377-393. https://doi.org/10.1016/j.berh.2014.07.006

Issa, L. F., Nagy A., Seleem, N. A., Bakheit, A. M., Baky, A. A., \& Alotaibi, A. F. (2016). Low BP among undergraduate students at Taif University - Saudi Arabia.

Jarque, C. M., \& Bera, A. K. (1987). A test for normality of observations and regression residuals. International Statistical Review, 2, 163-172. https://doi.org/10.2307/ 1403192

Jovinius, J. (2015). An investigation of the effect of geographical location of schools to the students' academic performance: A case of public secondary schools in Muleba District (Doctoral dissertation, The Open University of Tanzania).

Kang, Y. Y., Wang, M. J. J., \& Lin, R. (2009). Usability evaluation of e-books. Displays, 30(2), 49-52. https://doi.org/10.1016/j.displa.2008.12.002

Kassenboehmer, S., \& Schmidt, C. (2011). Beyond GDP and back: What is the value-added by additional components of welfare measurement?. https://doi.org/10.2139/ssrn. 1753686

Kędra, A., \& Czaprowski, D. (2013). Epidemiology of back pain in children and youth aged 10-19 from the area of the Southeast of Poland. BioMed Research International (2013). https://doi.org/10.1155/2013/506823

Kellis, E., \& Emmanouilidou, M. (2010). The effects of age and gender on the weight and use of schoolbags. Pediatric Physical Therapy, 22(1), 17-25. https://doi.org/10.1097/ PEP.0b013e3181cbf852

Khalid, F., Amjad, F., Ashfaq Ahmad, S. A. G., \& Hanif, M. K. (2018). Frequency of neck pain due to school bag usage among students of public high schools in Lahore, Pakistan. Pakistan Pediatric Journal, 42(3), 207-211.
Kim, J. H., Aulck, L., Thamsuwan, O., Bartha, M. C., \& Johnson, P. W. (2014). The effect of key size of touch screen virtual keyboards on productivity, usability, and typing biomechanics. Human Factors, 56(7), 1235-1248. https://doi.org/10.1177/0018720814531784

King, S., Chambers, C. T., Huguet, A., Macnevin, R. C., Mcgrath, P. J., Parker, L., \& Macdonald, A. J. (2011). The epidemiology of chronic pain in children and adolescents revisited: A systematic review. Pain, 152(12), 2729-2738. https://doi.org/10.1016/j.pain.2011.07.016

Korovessis, P., Koureas, G., \& Papazisis, Z. (2004). Correlation between backpack weight and way of carrying, sagittal and frontal spinal curvatures, athletic activity, and dorsal and low BP in schoolchildren and adolescents. Clinical Spine Surgery, 17(1), 33-40. https://doi.org/10.1097/00024720200402000-00008

Kristjansdottir, G., \& Rhee, H. (2002). Risk factors of BP frequency in schoolchildren: A search for explanations to a public health problem. Acta Paediatrica, 91(7), 849-854. https://doi.org/10.1111/j.1651-2227.2002.tb03339.x

Kumar, G., Chhabra, A., Dewan, V., \& Yadav, T. P. (2017). Idiopathic musculoskeletal pain in Indian childrenprevalence and impact on daily routine. Revistabrasileira De Reumatologia, 57(1), 8-14. https://doi.org/10.1016/ j.rbr.2015.03.005

Kwon, M. A., Shim, W. S., Kim, M. H., Gwak, M. S., Hahm, T. S., Kim, G. S., Kim, C. S., Choi, Y. H., Park, J. H., Cho, H. S., \& Kim, T. H. (2006). A correlation between low BP and associated factors: A study involving 772 patients who had undergone general physical examination. Journal of Korean Medical Science, 21(6), 1086-1091. https://doi.org/10.3346/ jkms.2006.21.6.1086

Larson, J. (2009). Educational psychology: cognition and learning, individual differences and motivation. Nova Science Publishers.

Leboeuf-Yde, C., Wedderkopp, N., Andersen, L. B., Froberg, K., \& Hansen, H. S. (2002). BP reporting in children and adolescents: The impact of parents' educational level. Journal of Manipulative and Physiological Therapeutics, 25(4), 216-220. https://doi.org/10.1067/mmt.2002.123172

Lee, S. P., Hsu, Y. T., Bair, B., Toberman, M., \& Chien, L. C. (2018). Gender and posture are significant risk factors to musculoskeletal symptoms during touchscreen tablet computer use. Journal of Physical Therapy Science, 30(6), 855-861. https://doi.org/10.1589/jpts.30.855

Leveille, S. G., Ling, S., Hochberg, M. C., Resnick, H. E., Bandeen-Roche, K. J., Won, A., \& Guralnik, J. M. (2001). Widespread musculoskeletal pain and the progression of disability in older disabled women. Annals of Internal Medicine, 135(12), 1038-1046. https://doi.org/10.7326/ 0003-4819-135-12-200112180-00007

Lewandowski, J., \& Lukaszewska, K. (2014). Characteristics of $\mathrm{BP}$ in polish youth depending on place of residence. Annals of Agricultural and Environmental Medicine, 21(3). https://doi.org/10.5604/12321966.1120618 
Limon, S., Valinsky, L. J., \& Ben-Shalom, Y. (2004). Children at risk: Risk factors for low BP in the elementary school environment. Spine, 29(6), 697-702. https://doi.org/ 10.1097/01.BRS.0000116695.09697.22

Lindström, B., \& Eriksson, M. (2011). From health education to healthy learning: Implementing salutogenesis in educational science. Scandinavian Journal of Public Health, 39(6_suppl), 85-92. https://doi.org/10.1177/14034948 10393560

Lingard, B., \& Rawolle, S. (2010). Globalization and the rescaling of education politics and policy. New Thinking in Comparative Education. Honouring Robert Cowen, pp. 33-52. https://doi.org/10.1163/9789460913051_005

Linton, S. J. (1990). Risk factors for neck and BP in a working population in Sweden. Work and Stress, 4(1), 41-49. https://doi.org/10.1080/02678379008256963

López-Aragón, L., López-Liria, R., Callejón-Ferre, Á. J., \& Gómez-Galán, M. (2017). Applications of the standardized nordic questionnaire: A review. https://doi.org/10.3390/ su9091514

Malhotra, K., \& Nistane, R. H. (2016). Study of obesity and hypertension in adolescents and their relationship with anthropometric indices. International Journal of Contemporary Pediatrics, 3(3), 1014-1021. https://doi.org/10.18203/2349-3291.ijcp20162383

Malik, L. A., Pasha, M. U., Khalid, S., Ahmad, A., \& Gilani, S. A. (2017). Prevalence of neck pain among undergraduate students of lahore. International Journal of Scientific \& Engineering Research.

Mcbeth, J., \& Jones, K. (2007). Epidemiology of chronic musculoskeletal pain. Best Practice and Research Clinical Rheumatology, 21(3), 403-425. https://doi.org/10.1016/ j.berh.2007.03.003

Mcgrady, A., \& Moss, D. (2018). Integrative pathways: Navigating chronic illness with a mind-body-spirit approach. Springer. https://doi.org/10.1007/978-3-319-89313-6

Melo-Marins, D. D., Carvalho, R. G. D. S., \& Gomes, L. E. (2015). Weight of school material and BP in students leaving their books at school. RevistaDor, 16(4), 276-279. https://doi.org/10.5935/1806-0013.20150056

Mikkelsson, M., Salminen, J. J., \& Kautiainen, H., (1997a). Non-specific musculoskeletal pain in preadolescents. Prevalence and 1-year persistence. Pain, 73(1), 29-35. https://doi.org/10.1016/S0304-3959(97)00073-0

Mikkelsson, M., Sourander, A., Piha, J., \& Salminen, J. J. (1997b). Psychiatric symptoms in preadolescents with musculoskeletal pain and fibromyalgia. Pediatrics, 100(2), 220-227. https://doi.org/10.1542/peds.100.2.220

Mikkonen, P., Heikkala, E., Paananen, M., Remes, J., Taimela, S., Auvinen, J., \& Karppinen, J. (2016). Accumulation of psychosocial and lifestyle factors and risk of low BP in adolescence: A cohort study. European Spine Journal, 25(2), 635-642. https://doi.org/10.1007/s00586-015-4065-0
Milbradt, S. N., Pranke, G. I., Texeira, C. S., Lemos, L. F., Alves, R. F., \& Mota, C. B. (2011). Aspectos da coluna vertebral relacionados a postura em crianças e adolescentes em idade escolar [Spine aspects related to posture in schoolage children and adolescents]. Fisioter Bras, 12(2), 127-132. https://doi.org/10.33233/fb.v12i2.812

Miller, S. J. (2006). The method of least squares. Mathematics Department Brown University, pp.1-7.

Moore, M. J., White, G. L., \& Moore, D. L. (2007). Association of relative backpack weight with reported pain, pain sites, medical utilization, and lost school time in children and adolescents. Journal of School Health, 77(5), 232-239. https://doi.org/10.1111/j.1746-1561.2007.00198.x

Muppidi, G. E., John, A. S., Angel, M. R., Thomvic, M. R., Rebekah, G., \& Padankatti, S. M. (2019). Burdened by the bag: A school-based cross-sectional survey. The Indian Journal of Occupational Therapy, 51(4), 140. https://doi.org/10.4103/ijoth.ijoth_13_19

Mwaka, E. S., Munabi, I. G., Buwembo, W., Kukkiriza, J., \& Ochieng, J. (2014). Musculoskeletal pain and school bag use: A cross-sectional study among Ugandan pupils. BMC Research Notes, 7(1), 222. https://doi.org/10.1186/17560500-7-222

Natasha, A. A., Syukri, A. A., Diana, M. K. S. N., Ima-Nirwana, S., \& Chin, K. Y. (2018). The association between backpack use and low back pain among pre-university students: A pilot study. Journal of Taibah University Medical Sciences, 13(2), 205-209. https://doi.org/10.1016/j.jtumed.2017.06. 005

O’Brien, E. M., \& Dervarics, C. (2010). Charter schools: Finding out the facts. Center for Public Education.

Panicker, R. K., \& Sandesh, T. S. (2014). Prevalence of musculoskeletal pain in school going adolescents using school bags: A co-relational research. International Journal of Therapies and Rehabilitation Research, 3(4), 1. https://doi.org/10.5455/ijtrr.00000039

Papadopoulou, D., Malliou, P., Kofotolis, N., Emmanouilidou, M. I., \& Kellis, E. (2014). The association between grade, gender, physical activity, and back pain among children carrying schoolbags. Archives of Exercise in Health \& Disease, 4(1).

Pascoe, D. D., Pascoe, D. E., Wang, Y. T., Shim, D. M., \& Kim, C. K. (1997). Influence of carrying book bags on gait cycle and posture of youths. Ergonomics, 40(6), 631-640. https://doi.org/10.1080/001401397187928

Paušić, J., \& Rausavljević, N. (2009). Changes in children's posture developed from first to third grade of elementary school. Kinesiologia Slovenica, 15(3), 1-7.

Paušić, J., Kujundžić, H., \& Penjak, A. (2013). Possible influences of a heavy backpack on BP syndrome in primary school children. Croatian Journal of Education, 15(2), 275287.

Perrone, M., Orr, R., Hing, W., Milne, N., \& Pope, R. (2018). The impact of backpack loads on school children: A critical narrative review. International Journal of Environmental Research and Public Health, 15(11), 2529. https://doi.org/10.3390/ijerph15112529 
Power, C. (1991). Social and economic background and class inequalities in health among young adults. Social Science \& Medicine, 32(4), 411-417. https://doi.org/10.1016/02779536(91)90342-A

President Ronald Reagan, "Remarks at a briefing for the White House work-shop on choice in education," January 10, 1989.

Quiggin, J. (1999). Human capital theory and education policy in Australia. Australian Economic Review, 32(2), 130-144. https://doi.org/10.1111/1467-8462.00100

Rai, A., \& Agarawal, S. (2013). Back problems due to heavy backpacks in school children. IOSR Journal of Humanities and Social Science, 10, 1-5. https://doi.org/10.9790/08371062226

Rajan, P., \& Koti, A. (2013). Ergonomic assessment and musculoskeletal health of the underprivileged school children in Pune, India. Health Promotion Perspectives, 3(1), 36.

Robinson, C. (2014). Human capital, education, achievement and learning. Department of Economics, University of Western Ontario

Rodrigues, S., Montebelo, M. I. L., \& Teodori, R. M. (2008). Distribuição da força plantar e oscilação do centro de pressão em relação ao peso e posicionamento do material escolar [Distribution of plantar force and oscillation of the pressure center in relation to the weight and positioning of school supplies]. Revista Brasileira De Fisioterapia, 12(1). https://doi.org/10.1590/S1413-35552008000100009

Rontogiannis, D., Tsaklis, P., Mavromoustakos, S., \& Kottaras, S. (2017). Comparison between two different types of school bags and musculoskeletal symptoms in primary school students. IETI Trans Ergon Saf, 1(2), 11-21.

Sampaio, M. H. L. D. M., Oliveira, L. C. D., Pinto, F. J. M., Muniz, M. Z. A., Gomes, R. C. T. F., \& Coelho, G. R. L. (2016). Postural changes and pain in the academic performance of elementary school students. Fisioterapia Em Movimento, 29(2), 295-303. https://doi.org/10.1590/ 0103-5150.029.002.A008

Sato, T., Ito, T., Hirano, T., Morita, O., Kikuchi, R., Endo, N., \& Tanabe, N. (2008). Low BP in childhood and adolescence: A cross-sectional study in Niigata City. European Spine Journal, 17(11), 1441. https://doi.org/10.1007/s00586-0080788-5

Schofield, D. J., Shrestha, R. N., Cunich, M., Tanton, R., Kelly, S., Passey, M. E., \& Veerman, L. J. (2015). Lost productive life years caused by chronic conditions in Australians aged 45-64 years, 2010-2030. Medical Journal of Australia, 203(6), 260-260. https://doi.org/10.5694/mja15.00132

Schultz, T. W. (1961). Investment in human capital. The American Economic Review, 51(1), 1-17.

Shahid, G., Aziz, K., Arif, A., \& Fahim, M. F. (2018). Prevalence of musculoskeletal pain due to heavy backpacks in school going children of Karachi. International Journal of Physical Medicine \& Rehabilitation, 6(471), 2. https://doi.org/10.4172/2329-9096.1000471
Shan, Z., Deng, G., Li, J., Li, Y., Zhang, Y., \& Zhao, Q. (2013). Correlational analysis of neck/SP and low BP with the use of digital products, physical activity and psychological status among adolescents in Shanghai. Plos One, 8(10), P.E78109. https://doi.org/10.1371/journal.pone.0078109

Siambanes, D., Martinez, J. W., Butler, E. W., \& Haider, T. (2004). Influence of school backpacks on adolescent back pain. Journal of Pediatric Orthopaedics, 24(2), 211-217. https://doi.org/10.1097/01241398-200403000-00015

Siegenthaler, E., Wurtz, P., \& Groner, R. (2010). Improving the usability of e-book readers. Journal of Usability Studies, 6(1), 25-38.

Siivola, S. (2003). Neck and SP in a young population: Prevalence and etiological factors. Oulunyliopisto.

Siivola, S. M., Levoska, S., Latvala, K., Hoskio, E., Vanharanta, H., \& Keinänen-Kiukaanniemi, S. (2004). Predictive factors for neck and SP: A longitudinal study in young adults. Spine, 29(15), 1662-1669. https://doi.org/10.1097/01.BRS. 0000133644.29390.43

Spiteri, K., Busuttil, M. L., Aquilina, S., Gauci, D., Camilleri, E., \& Grech, V. (2017). Schoolbags and BP in children between 8 and 13 years: A national study. British Journal of Pain, 11(2), 81-86. https://doi.org/10.1177/2049463717695144

Springer, S., Gleicher, H., \& Hababou, H. (2018). Attitudes and beliefs about musculoskeletal pain and its association with pain neuroscience knowledge among physiotherapy students in Israel. Israel Journal of Health Policy Research, 7(1), 67. https://doi.org/10.1186/s13584-018-0266-4

Springett, A. G., \& Wise, J. E. (2007). Promoting healthy backs in schools: An evaluative study. Health Education, 107(5), 463-479. https://doi.org/10.1108/09654280710778592

Syazwan, A. I., Azhar, M. M., Anita, A. R., Azizan, H. S., Shaharuddin, M. S., Hanafiah, J. M., Muhaimin, A., Nizar, A., Rafee, B. M., Ibthisdam, A. M., \& Kasani, A. (2011). Poor sitting posture and a heavy schoolbag as contributors to musculoskeletal pain in children: an ergonomic school education intervention program. Journal of Pain Research, 4, 287. https://doi.org/10.2147/JPR.S22281

Tantawy, S. A., Abdul Rahman, A., \& Abdul Ameer, M. (2017). The relationship between the development of musculoskeletal disorders, body mass index, and academic stress in Bahraini University students. The Korean Journal of Pain, 30(2), 126-133. https://doi.org/10.3344/ kjp.2017.30.2.126

Taras, H. (2005). Nutrition and student performance at school. Journal of School Health, 75(6), 199-213. https://doi.org/10.1111/j.1746-1561.2005.00026.x

Triki, M., Koubaa, A., Masmoudi, L., Fellmann, N., \& Tabka, Z. (2015). Prevalence and risk factors of low BP among undergraduate students of a sports and physical education institute in Tunisia. Libyan Journal of Medicine, 10(1), 26802. https://doi.org/10.3402/ljm.v10.26802

Uyal, B. N., Yel, E. B., \& Korhan, O. (2017). Impact of traditional education and tablet-assisted education on students: A comparative analysis. Eurasia Journal of Mathematics, Science and Technology Education, 13(11), 7205-7213. https://doi.org/10.12973/ejmste/79045 
Van Heerden, M., \& Van Belle, J. P. (2013). Using e-readers and tablets in higher education: A student perspective. In The fourth international conference on e-learning (ICEL2013) (pp. 154-166).

Viester, L., Verhagen, E. A., Hengel, K. M. O., Koppes, L. L., Van Der Beek, A. J., \& Bongers, P. M. (2013). The relation between body mass index and musculoskeletal symptoms in the working population. BMC Musculoskeletal Disorders, 14(1), 238. https://doi.org/10.1186/1471-2474-14-238

Vijay, S., \& Ide, M. (2016). Musculoskeletal neck and BP in undergraduate dental students at a UK dental school-A cross-sectional study. British Dental Journal, 221(5), 241. https://doi.org/10.1038/sj.bdj.2016.642

Von Cramon-Taubadel, S. (1998). Estimating asymmetric price transmission with the error correctionrepresentation: An application to the german pork market. European Review of Agricultural Economics, 25, 1-18. https://doi.org/10.1093/ erae/25.1.1

Walicka-Cupryś, K., Skalska-Izdebska, R., Rachwał, M., \& Truszczyńska, A. (2015). Influence of the weight of a school backpack on spinal curvature in the sagittal plane of sevenyear-old children. Biomed Research International (2015). https://doi.org/10.1155/2015/817913

Wáng, Y. X. J., Wáng, J. Q., \& Káplár, Z. (2016). Increased low BP prevalence in females than in males after menopause age: Evidences based on synthetic literature review. Quantitative Imaging in Medicine and Surgery, 6(2), 199. https://doi.org/10.21037/qims.2016.04.06
Watson, K. D., Papageorgiou, A. C., Jones, G. T., Taylor, S., Symmons, D. P., Silman, A. J., \& Macfarlane, G. J. (2002). Low BP in schoolchildren: Occurrence and characteristics. Pain, 97(1-2), 87-92. https://doi.org/10.1016/S03043959(02)00008-8

White, H. (1980). A heteroskedasticity-consistent covariance matrix estimator and a direct test for heteroskedasticity. Econometrica: Journal of the Econometric Society, pp. 817838. https://doi.org/10.2307/1912934

Wigram, J. (2002). Why is low BP common in adolescence. Education and Health, 20, 36-37.

Wooldridge, J. M. (2015). Introductory econometrics: A modern approach. Nelson Education.

Yang, T. C., Matthews, S. A., \& Chen, V. Y. J. (2014). Stochastic variability in stress, sleep duration, and sleep quality across the distribution of body mass index: Insights from quantile regression. International Journal of Behavioral Medicine, 21(2), 282-291. https://doi.org/10.1007/s12529-013-92932

Yelin, E. (1997). The earnings, income, and assets of persons aged 51-61 with and without musculoskeletal conditions. The Journal of Rheumatology, 24(10), 2024-2030.

Yeun, Y. R., \& Han, S. J. (2017). Factors associated with neck/shoulder pain in young adults. Biomedical Research, 28(16).

Yoon, J. G. (2014). Correlations between muscle activities and strap length and types of school bag during walking. Journal of Physical Therapy Science, 26(12), 1937-1939. https://doi.org/10.1589/jpts.26.1937

Zimerman, M. (2011). E-readers in an academic library setting. Library Hi Tech, 29(1), 91-108. https://doi.org/10.1108/ 07378831111116930 